Pirineos. Revista de Ecología de Montaña

Vol. 175

Jaca, Enero-Diciembre, 2020, e061

ISSN-1: 0373-2568

https://doi.org/10.3989/pirineos.2020.175011

\title{
GEOMORFOSITIOS DE INTERÉS VOLCANO TURÍSTICO EN UNA MONTAÑA SUBTROPICAL: EL PARQUE NACIONAL DEL TEIDE (CANARIAS, ESPAÑA)
}

\section{Geomorphosites with volcano tourism interest in a subtropical mountain: Teide National Park (Canary Islands, Spain)}

\author{
Javier Dóniz Páez ${ }^{1,3}$ *, Rafael Becerra Ramírez²,3 \\ ${ }^{1}$ GEOTURVOL-Departamento de Geografía e Historia, Universidad de La Laguna, Facultad de Humanidades, \\ C/ Prof. José Luis Moreno Becerra, s/n, 38200, Tenerife, España. \\ ${ }^{2}$ GEOVOL-Departamento de Geografía y Ordenación del Territorio. Universidad de Castilla-La Mancha, Facultad de Letras. \\ Avda. Camilo José Cela s/n, 13071, Ciudad Real. España. \\ ${ }^{3}$ Instituto Volcanológico de Canarias (INVOLCAN). Tenerife, España
}

\author{
Identificador ORCID de los autores y e.mail: \\ Javier Dóniz-Páez: https://orcid.org/0000-0002-7789-7720. Email: jdoniz@ull.edu.es \\ Rafael Becerra-Ramírez: https://orcid.org/0000-0001-7778-4892.Email: rafael.becerra@uclm.es \\ * Autor de contacto
}

\begin{abstract}
Recibido: 19-06-2020. Aceptado: 31-08-2020. Fecha de publicación on-line: 22-10-2020
Citation / Cómo citar este artículo: Dóniz Páez, J., Becerra Ramírez, R. (2020). Geomorfositios de interés volcano turístico en una montaña subtropical: el Parque Nacional del Teide (Canarias, España). Pirineos, 175, e061. https://doi. org/10.3989/pirineos.2020.175011

RESUMEN: El Parque Nacional del Teide (PNT) en Tenerife recibe más de tres millones de visitantes al año atraídos por la diversidad paisajística de una alta montaña subtropical que es Patrimonio de la Humanidad de la Unesco. El objetivo del trabajo es seleccionar y evaluar geomorfositios con interés volcano turístico que diversifiquen la oferta dentro del PNT y en la isla. La metodología empleada se basa en identificar y seleccionar los sitios más representativos, mejor conservados y más accesibles y evaluar sus valores científicos, añadidos y de uso y gestión. Los diez geomorfositios seleccionados son los que mejor representan la diversidad del patrimonio natural y cultural del PNT y están acordes con la aproximación geográfica del geoturismo, acogiendo casi la totalidad de los atractivos del volcano turismo. En líneas generales los valores científicos $(0,62)$ de todos los geomorfositios estudiados están por encima de los añadidos $(0,44)$, lo que parece estar acorde con la protección y conservación de este sitio como parque nacional.
\end{abstract}

PALABRAS CLAVE: Volcanes; geomorfositios; geoturismo; volcanoturismo; Parque Nacional del Teide; España.

ABSTRACT: The Teide National Park (TNP) on Tenerife island, receives more than 3 million visitors per year attracted by the landscape diversity of a subtropical high mountain that is a Unesco World Heritage Site. The aim of this work is to select and evaluate geomorphosites with a volcano tourism interest diversify the tourist offer within 
the TNP and on the island. The methodology used is based on indentifying and selecting the most representative, best conserved and more accesible sites, and evaluating their scientific, added and use and management values. The ten geomorphosites selected are the most representative of the diversity of the natural and cultural heritage of TNP, which are consistent with the geographical approach of geotourism, hosting almost all of the volcano tourism attractions. In general, the scientific values $(0.62)$ from all the geomorphosites studied are above the added values $(0.44)$, which seems to be in accordance with protection and conservation of the national park.

KEY WORDS: Volcanoes; geomorphosites; geotourism; volcano tourism; Teide National Park; Spain.

\section{Introducción}

El turismo es una actividad diversa, compleja y dinámica. Estas razones explican, en parte, las importantes trasformaciones que están experimentando los destinos turísticos maduros. Entre estos cambios, cabe destacar los aspectos legislativos que regulan la actividad turística en términos de reducir la oferta o de proponer modelos de turismo más sostenibles afectando al medio natural, sociocultural y económico. En esta misma línea van las intervenciones en el espacio público y privado, cuyo fin es rehabilitar, renovar, adaptar y modificar las infraestructuras y equipamientos urbanos hacia los nuevos requerimientos del turismo. Ambas modificaciones van acompañadas de la irrupción de nuevas formas de ocio turístico acordes con una demanda cada vez más exigente e informada en un escenario turístico cambiante y sostenible. En este contexto, los nuevos productos y experiencias turísticas se presentan como una opción válida para dar respuesta a los importantes cambios que están afectando al turismo, especialmente en destinos consolidados cuyo protagonismo es el sol y la playa.

En este sentido, el geoturismo se presenta como una modalidad de turismo relativamente reciente que se ha incrementado en los últimos años (Wang et al., 2014; Ólafsdóttir \& Dowling, 2014; Ruban, 2015; Dowling \& Newsone, 2018) coincidiendo, sobre todo, con la creación y consolidación de las redes europea y mundial de geoparques, en donde España con quince es el primer país europeo y el segundo del mundo en número por detrás de China. El carácter reciente e innovador del geoturismo es responsable tanto del debate científico en torno a su concepto, como de la diversidad de actividades que puede englobar. La literatura científica agrupa al geoturismo en torno a dos aproximaciones: geológica y geográfica. En la primera se le relaciona con un tipo o forma de turismo asociada con recursos y atractivos geológicos y geomorfológicos con un alto componente estético y/o escénico (Hose, 1995, 2008; Newsome \& Dowling, 2010; Carcavilla et al., 2011; Ólafsdóttir \& Tverijonaite, 2018). Por su parte, la aproximación geográfica tiene una visión más integral y sostenible (Tourtellot, 2000; Stoke et al., 2003; Pralong, 2006; National Geographic, 2010; Arouca Declaration, 2011; Millán, 2011; Olson \& Dowling, 2018; Sánchez-Cortez \& Simbaña-Tasiguano, 2018; DónizPáez et al., 2019; Kubalíková, 2019), entendiendo que el geoturismo se basa en la concepción de que el medio ambiente lo integran aspectos abióticos, bióticos y culturales
(Dowling, 2013; Chen et al., 2015, 2020; Dowling \& Newsone, 2018). Es evidente que bajo el paraguas de cada una de las aproximaciones se pueden reconocer productos geoturísticos diferentes, pero que en ningún caso tienen que ser excluyentes (Dowling \& Newsone, 2018) y donde, en ocasiones, es el valor educativo del geoturismo el nexo de unión de ambas aproximaciones.

El geoturismo en entornos volcánicos se ha incrementado igualmente en los últimos años (Erfurt-Cooper et al., 2015; Erfurt-Cooper, 2018). El volcano turismo consiste en visitar volcanes activos, dormidos o extintos para su estudio y exploración, siempre que dispongan de un patrimonio geológico y geomorfológico suficientemente interesante para atraer visitantes (Sigurdsson \& Lopes, 2000; Erfurt-Cooper \& Cooper, 2010; Dóniz-Páez, 2012, 2014; Dowling, 2013; Davis et al., 2013; Erfurt-Cooper, 2014; Master, 2016; Różycka \& Migoń, 2018; Aquino et al., 2019; Mateo et al., 2019; Suhud \& Allan, 2019). En sintonía con el carácter más integral y geográfico del geoturismo, el volcano turismo acoge multitud de recursos y atractivos turísticos vinculados con el patrimonio natural y cultural (Megerssa et al., 2019), entre los que destacan el paisaje, las manifestaciones eruptivas, las fuentes termales y los spas, los deportes de aventura y riesgo, el ecoturismo y turismo científico, las playas de arena negra o roja, los parques culturales y la relación entre los volcanes y la religión (Sigurdsson \& Lopes, 2000; Dóniz-Páez, 2014). Por tanto, teniendo en cuenta que el volcano turismo está englobado dentro del geoturismo (Erfurt-Cooper, 2018), sí que parece que haya una aproximación más integral, holística y geográfica del volcano turismo al tenerse en cuenta tanto aspectos del patrimonio natural (formas del relieve, vegetación, etc.) como del cultural (religión, arqueología, historia, aguas, etc.) asociado con los volcanes (Dóniz-Páez et al., 2019).

En lo que sí que parece haber cierta coincidencia es en que para determinar qué lugares tienen interés geoturístico, independientemente del tipo de relieve, es necesario identificar, inventariar, seleccionar y evaluar geositios o geomorfositios. Aunque es cierto que hay un interesante debate científico en torno a ambos conceptos, la principal diferencia entre unos y otros está en que los primeros se caracterizan principalmente por sus valores científicos, mientras que los geomorfositios son más amplios y engloban también valores añadidos de tipo ecológico, cultural, estético o económico (Kubalíková, 2013, 2019). Las primeras definiciones de geomorfositios señalan que son formas del relieve que adquieren valores científicos, cul- 
turales, históricos, estéticos y socioeconómicos en función de cómo la humanidad los ha percibido o explotado (Panizza, 2001; Reynard \& Panizza, 2005). Incluso para los geomorfositios volcánicos se señala que su patrimonio científico debe estar vinculado a su patrimonio cultural y mantener relaciones con la geología, la historia de la humanidad, el arte o la literatura (Joyce, 2009; PérezUmaña et al., 2019). Por ello, desde el punto de vista geoturístico parece ser que los geomorfositios son más apropiados que los geositios (Kubalíková, 2013, 2019). En esta misma línea se manifiesta el grupo de trabajo de la IAG (International Association of Geomorphologists) cuando señala que entre los objetivos de las investigaciones sobre geomorfositios están su promoción turística, su inclusión en cursos sobre ecoturismo, senderismo o desarrollo local y su relación pública con programas de geoconservación y geoturismo como los geoparques (www.geomorph.org/geomorphosites-working-group). Por tanto, las principales razones para elegir los geomorfositios y determinar el interés geoturístico de un lugar están asociadas con el carácter más global de estos, acordes con la acepción geográfica y los principios del geoturismo de la National Geographic Society (2020) pero, también, con su importancia como recurso educativo y con el papel que desempeñan los paisajes geomorfológicos como atractivos turísticos (Romero-Díaz \& Belmonte, 2002) en su vertiente más escénica o paisajística.

El objetivo de este trabajo es identificar, inventariar, seleccionar y evaluar geomorfositios volcánicos con interés geoturístico en el Parque Nacional del Teide (PNT) para fortalecer y fomentar las actividades de volcano turismo, que diversifiquen su oferta y que puedan contribuir a su mejor gestión. La elección del PNT como área de estudio se debe a que es la única macroestructura volcánica reconocida en Canarias en cuyo interior están, exclusivamente, los dos estratovolcanes activos y diferenciados, únicos en el contexto del volcanismo insular de intraplaca del mundo (Carracedo, 2006); que el Teide es el volcán más alto del Atlántico y el tercero del mundo desde su base en el fondo del océano (Carracedo \& Troll, 2013); que se trata del espacio que cuenta con la mayor diversidad de formas y procesos de relieve, tanto asociados al volcanismo como con el desmantelamiento de Tenerife; que es el parque nacional más visitado de España con una media de más de tres millones anuales de visitantes; que es Bien Natural Patrimonio de la Humanidad atendiendo a los criterios estéticos y geológicos (Martínez de Pisón et al., 2009) y que, hasta ahora, no se había aplicado esta metodología u otras similares para valorar el potencial volcano turístico de sus geomorfositios y sí se ha realizado para otros espacios de Canarias con un elevado potencial para el volcano turismo como los geoparques globales de la Unesco de El Hierro y Lanzarote y Archipiélago Chinijo (Figura 1).

\section{2. Área de estudio}

El Parque Nacional del Teide se localiza en las cumbres centrales de la isla de Tenerife (Figura 2) y fue decla- rado como tal por Decreto en 1954 y reclasificado en 1981 (Ley 5/1981), y posteriormente fue declarado Bien Natural Patrimonio de la Humanidad designado por la UNESCO en 2007 (ref. 1258). Sus principales valores están asociados al relieve volcánico y una singular flora y fauna que se ha adaptado a las particulares condiciones ambientales propias de una alta montaña volcánica subtropical. Igualmente, su patrimonio natural y cultural han sido un referente científico durante siglos (González-Lemus \& Sánchez, 2004), asociado a modelos de interpretación de los fenómenos eruptivos de estratovolcanes y la organización altitudinal de la vegetación (HernándezGonzález, 2005; Gebauer, 2014). En la actualidad este espacio protegido conforma el área natural por antonomasia de la isla y su complejidad se resuelve a través de un variado mosaico de paisajes (Martínez de Pisón et al., 2009) protagonizado por la geodiversidad de sus volcanes y la originalidad de su vegetación.

El paisaje del PNT se fundamenta en tres aspectos principales: los volcanes, la vegetación y el uso humano. La geología y la geomorfología son los protagonistas del paisaje volcánico del parque nacional. Los inicios de este sector se remontan a unos 3 millones de años (Ma) con la formación del primitivo Edificio Cañadas y de manera simultánea la construcción del volcanismo de rift (Martí et al., 1994), seguido de la formación de La Caldera de Las Cañadas y los orígenes del estratovolcán Teide-Pico Viejo hace unos 0,79 Ma (Ablay \& Martí, 2000) y llega hasta nuestros días con la erupción histórica de Narices del Teide en 1798. A lo largo de este período las manifestaciones volcánicas y los productos resultantes son mucho más heterogéneos que en los estadios iniciales de formación de Tenerife. La dinámica de las erupciones oscila entre las hawaianas, pasando por la de tipo estromboliano y estromboliano violento hasta las de carácter subpliniano. La naturaleza de los materiales emitidos es tanto básica como ácida, destacando entre estos últimos las traquitas y las fonolitas. Como consecuencia de este volcanismo dentro de los límites del parque nacional se pueden reconocer formas y procesos directamente relacionados con el fenómeno eruptivo (estratovolcanes, calderas, campos de volcanes, domos, cráteres, campos lávicos, mantos de pómez y lapilli, diques, pitones, etc.) y las de erosión y acumulación (barrancos, llanos endorreicos, abanicos aluviales, suelos estriados, dunas, etc.). Unas y otras son responsables de la geodiversidad del PNT, dando lugar a un elevado número de geomorfositios que son el grueso de los recursos y/o atractivos turísticos que se aprovechan dentro del parque nacional (Teide, Pico Viejo, Montaña Blanca-Rajada, Roques de García, La Fortaleza, Llanos de Ucanca, Narices del Teide, Pared de Las Cañadas, volcán de Fasnia, Montaña Mostaza, etc.).

La biogeografía del PNT tiene un papel secundario con respecto al relieve en el paisaje del mismo, destacando las diferentes configuraciones de un matorral de alta montaña volcánica subtropical. Sin embargo, desde el punto de vista florístico tiene un gran interés, no solo 


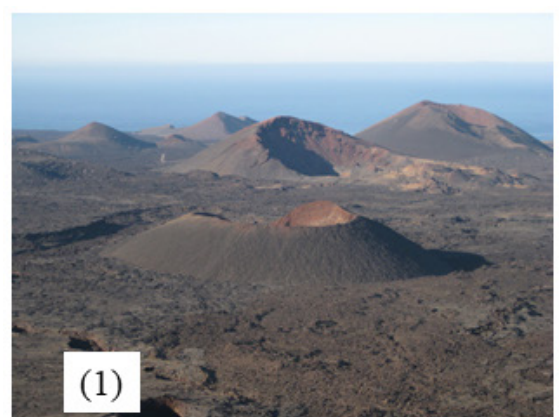

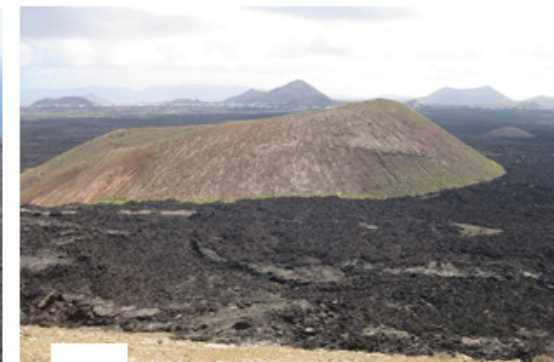

(2)
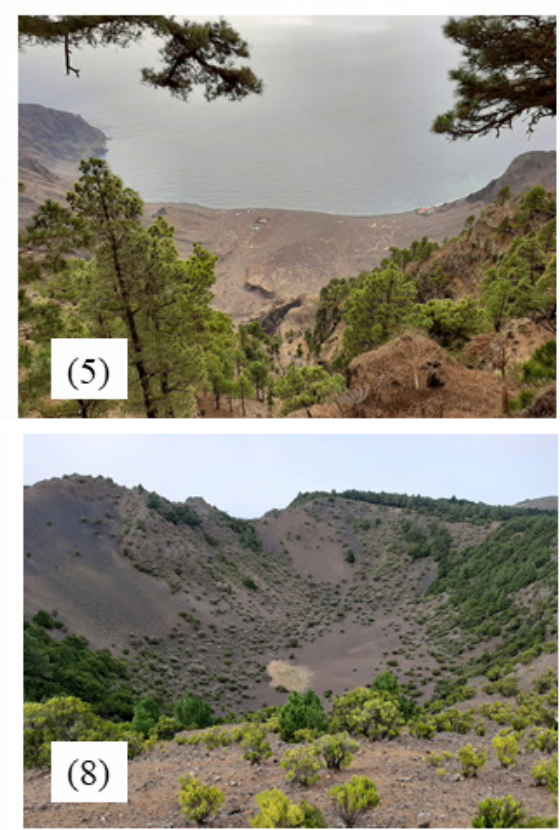
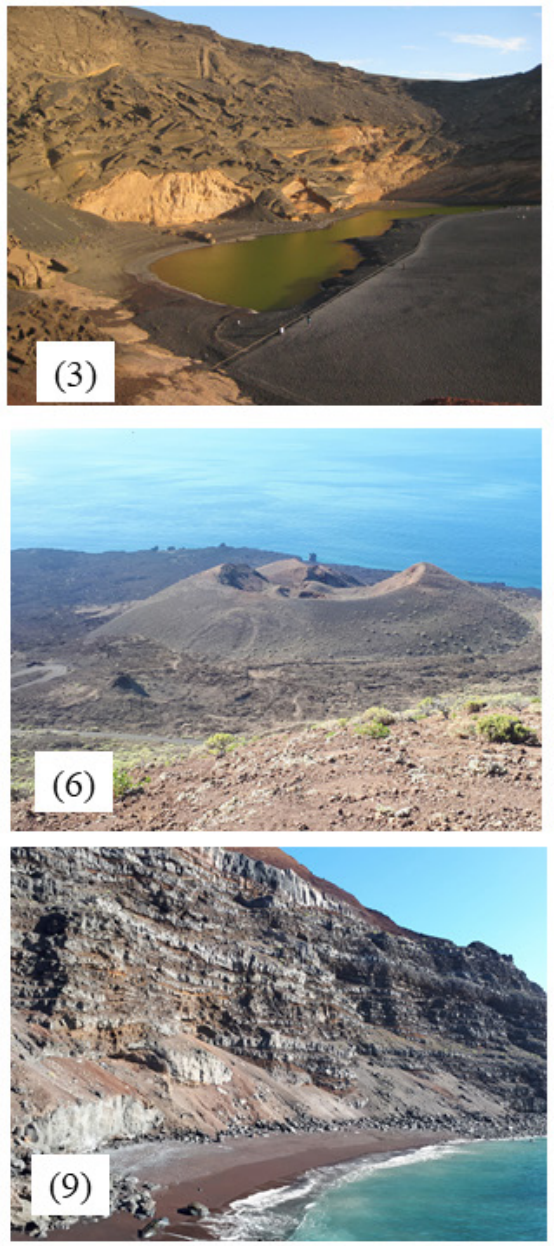

Figura 1. Paisajes geomorfológicos de los geoparques canarios. (1) Panorámica del Parque Nacional de Timanfaya en el geoparque de Lanzarote. (2) Volcán Montaña Caldereta y lavas de la erupción de 1730-1736 de Timanfaya en Lanzarote. (3) Volcán hidromagmático de El Golfo en Lanzarote. (4) Jameos del Agua en el tubo volcánico de La Corona en Lanzarote. (5) El deslizamiento de Las Playas en el Hierro. (6) Volcán múltiple de Las Calcosas en El Hierro. (7) Lavas aa y pahoehoe en Los Lajiales en el Hierro. (8) Cráter del volcán hidromagmático de Hoya Fileba en el Hierro. (9) Playa de arena roja de El Verodal en El Hierro. Figure 1. Geomorphological landscapes of canarian geoparks. (1) Panoramic view of the Timanfaya National Park in Lanzarote geopark. (2) Monogenetic cone of Montaña Caldereta and lava fields from the 1730-1736 Timanfaya eruption. (3) Hydromagmatic volcano of El Golfo in Lanzarote. (4) Jameos del Agua in La Corona lava tube in Lanzarote. (5) The Las Playas giant landslide in

El Hierro. (6) Las Calcosas multiple cinder cone in El Hierro. (7) Lavas aa and pahoehoe in Los Lajiales, El Hierro.

(8) Hydromagmatic crater of Fileba volcano in El Hierro geopark. (9) Red sand beach of El Verodal, El Hierro.

por la riqueza de especies, sino por el elevado número de endemismos (Martínez de Pisón et al., 2009). En este sentido, el catálogo de flora vascular del PNT recoge que, de los 168 taxones reconocidos, 58 son endemismos canarios y 33 tinerfeños y de estos últimos 12 son exclusivos del parque (Wildpret de la Torre \& MartínOsorio, 2004). Algo similar sucede con la fauna invertebrada que es rica y diversa (Arechavaleta \& Oromí, 2004); pero no la vertebrada que es bastante reducida y casi referida a la presencia de algunas aves y lagartos (Machado, 2004).

Las cumbres de la isla fueron claves para los guanches, pueblo aborigen de Tenerife, ya que desde época prehistórica se desarrolló una intensa actividad económica relacionada con el pastoreo. Fruto de esta ocupación encontramos vestigios distribuidos por casi toda la geografía del PNT, entre los que destacan restos arqueológicos de cabañas, refugios y paraderos pastoriles con utensilios líticos y cerámicos (Arnay de la Rosa, 2004). Además de estas evidencias arqueológicas, más recientemente los recursos del parque han sido explotados por parte de los tinerfeños (extracción de azufre, neveros, leña, carboneo, cañadas, pastoreo, apicultura, etc.). Al día de hoy, la originalidad de los valores culturales del parque descansa tanto en el referente que supuso para viajeros y científicos desde el siglo XVI al XVIII como en el contenido de la geografía fantástica asociada a mitos, leyendas, tradiciones, exploraciones, literatura, arte, etc. (González-Lemus \& Sánchez, 2004; Martínez de Pisón, et al., 2009; Carracedo \& Trol, 2013). 


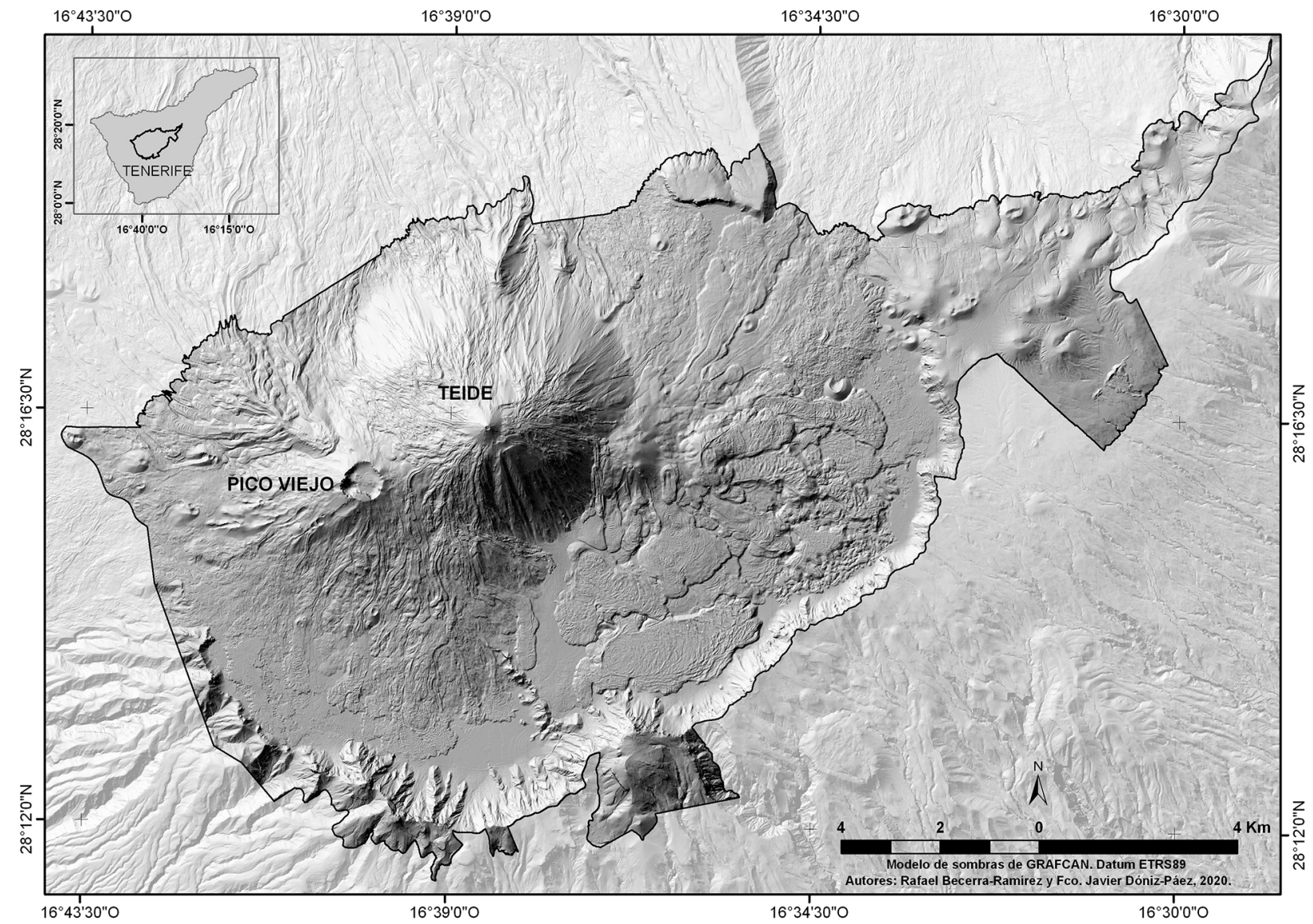

Figura 2. Localización del Parque Nacional del Teide. Fuente: Elaboración propia a partir del MDE de Grafcan. Figure 2. Location of Teide National Park. Source: Own elaboration from the DEM base of Grafcan.

\section{Material y métodos}

La identificación, inventario, selección y evaluación de los geomorfositios de interés geoturístico del PNT se basa en investigaciones previas (Reynard et al., 2007, 2016; Moufti et al., 2013; Bouzekraoui et al., 2017; Pérez-Umaña et al., 2019, 2020; Zangmo-Tefogoum et al., 2020). Este trabajo se desarrolló en tres fases: 1-identificación, inventario y selección de los geomorfositios; 2-caracterización de los lugares seleccionados y 3-evaluación de los geomorfositios teniendo en cuenta sus valores intrínsecos (científicos y adicionales o añadidos) y los de uso y gestión.

\subsection{Identificación, inventario y selección de los geomorfositios}

La identificación de los geomorfositios se realizó sobre cartografía topográfica, geológica y geomorfológica a diferentes escalas y con modelos digitales del terreno y el trabajo de campo durante varias campañas en los últimos veinte años. Para el inventario de los geomorfositios se ha tenido en cuenta si estos corresponden con formas y procesos del relieve que se presentan agrupados (Teide-Coladas Negras, volcanes de Samara-Reventada, Pared de Diego
Hernández, etc.) o de manera individual (Volcán de Fasnia, volcán de Narices del Teide, etc.); si están asociados con morfologías y dinámicas volcánicas directas (estratovolcanes, conos volcánicos, domos, cráteres, campos de lavas, etc.), o si son consecuencia del desmantelamiento erosivo y la acumulación (barrancos, taludes, llanos endorreicos, etc.), o fruto de ambos. En la selección de los diez geomorfositios finales se tuvo en cuenta que las formas elegidas fuesen representativas de la geodiversidad de las cuatro grandes unidades de paisaje definidas en el PNT (Teide-Pico Viejo, Atrio de Las Cañadas, Pared de Las Cañadas y los campos de volcanes-dorsales) (Martínez de Pisón et al., 2009), que estén bien conservadas y que sean accesibles a través de la red de senderos propia del parque nacional.

\subsection{Documentación de los geomorfositios}

La documentación incluyó dos tipos de datos. Por un lado, datos numéricos generales (coordenadas, elevación, etc.) que permiten ubicar el geomorfositio en un mapa de síntesis. Y, por otro lado, información cualitativa sobre la caracterización de los mismos (geología, geomorfología, geografía, ecología, historia, estética, etc.). Este segundo paso es clave para la evaluación de cada uno de los ítems 
durante la valoración de los geomorfositios. Ambos tipos de datos se recogieron en una ficha que facilita el tratamiento de la información.

\subsection{Evaluación de los geomorfositios}

La evaluación de los geomorfositios seleccionados sigue los postulados metodológicos implementados previamente en espacios tanto volcánicos como no. La base de esta metodología son las investigaciones de Reynard et al. (2007, 2016), pero incorporan las especificidades para las formas y los procesos eruptivos tal y como recogen publicaciones anteriores en territorios volcánicos (Dóniz-Páez et al., 2011; Becerra-Ramírez, 2013; Pérez-Umaña et al., 2019, 2020; Zangmo-Tefogoum et al., 2020). La evaluación de los geomorfositios tiene en cuenta los valores intrínsecos, subdivididos en científicos y adicionales o añadidos, y los de uso y gestión (Serrano \& González, 2005; Reynard et al., 2007). Los valores intrínsecos son los inherentes y específicos de cada geomorfositio (Reynard et al., 2016). Por otro lado, los de uso y gestión no se consideran como un valor del geomorfositio, por tanto, la información es recopilada y almacenada en una base de datos que puede ser utilizada para la clasificación, comparación y posteriormente para la gestión del lugar (Reynard et al., 2016). En este sentido, se entiende por tanto que las potenciales actividades educativas o geoturísticas, así como las necesidades de protección, no son parte de la "calidad" del geomorfositio y, por lo tanto, no deben considerarse como un valor del mismo (Reynard et al., 2016).
En la evaluación de los valores intrínsecos todos los autores consultados emplean una escala cuantitativa (Kubalíková, 2013; Reynard et al., 2016; Bouzekraoui et al., 2017; Pérez-Umaña et al., 2020; Zangmo-Tefogoum et al., 2020), mientras que para los de uso y gestión no siempre es así. En este sentido, hay trabajos en los que se desarrolla una evaluación cualitativa (Reynard et al., 2007, 2016) frente a aquellos en donde es cuantitativa (Serrano y González, 2005; González et al., 2014; Kubalíková, 2019). Ahora bien, en lo que todos coinciden es en el intervalo de la escala numérica para puntuar cada ítem, que va de 0,25 en 0,25 hasta un máximo de un punto, asignándole 0 cuando el valor es nulo y 1 si es muy alto. Con el fin de poder establecer comparaciones y definir un nivel jerárquico para cada geomorfositio se establece la siguiente clasificación: bajos si las puntuaciones son $<0,4$; medios si son $\geq 0,4 \mathrm{y}<0,6$; y altos si están entre $\geq 0,6$ y 1 (Bouzekraoui et al., 2017).

La evaluación de cada uno de los parámetros se realizó de manera grupal y estuvo sostenida por una amplia experiencia de campo de los miembros del equipo de investigación en el Parque Nacional del Teide durante años y en la consulta de la bibliografía sobre este tipo de metodologías. Los resultados se expresan en valores promedios para poder compararlos.

Los valores científicos se dividen en cuatro tipos de criterios: integridad, representatividad, rareza e interés. En la Tabla 1 se desglosan cada tipo de criterios y los valores cuantitativos que se le asignan.

Los valores adicionales o añadidos se dividen en cuatro tipos: ecológicos, estéticos, culturales y económicos y la mayoría de ellos a su vez se subdividen. En la Tabla 2 se desglosan dentro de cada valor los diferentes criterios y los valores cuantitativos.

Tabla 1. Criterios utilizados para la obtención de los valores científicos. Adaptado de Reynard et al. (2007, 2016).

Table 1. Criteria used for the assessment of the scientific value. Adapted from Reynard et al. (2007, 2016).

\begin{tabular}{|c|c|}
\hline Criterio & Valor \\
\hline $\begin{array}{l}\qquad \text { Integridad (I) } \\
\text { Estado de conservación del sitio. La mala conservación puede deberse a } \\
\text { factores naturales (por ejemplo, erosión) o factores humanos. }\end{array}$ & $\begin{array}{l}0=\text { Destruido } \\
0,25=\text { Prácticamente destruido } \\
0,5=\text { Parcialmente destruido } \\
0,75=\text { Ligeramente dañado } \\
1=\text { Intacto }\end{array}$ \\
\hline $\begin{array}{l}\text { Representatividad (R) } \\
\text { Se usa con respecto a un espacio de referencia (por ejemplo, comarca, } \\
\text { región, isla, país). Todos los sitios seleccionados deben cubrir los procesos } \\
\text { principales, activos o relictos, en el área de estudio }\end{array}$ & $\begin{array}{l}0=\text { Nulo } \\
0,25=\text { Débiles } \\
0,5=\text { Moderado } \\
0,75=\text { Alto } \\
1=\text { Muy alto }\end{array}$ \\
\hline $\begin{array}{l}\qquad \text { Rareza }(\mathbf{R z}) \\
\text { Se refiere a la rareza del sitio con respecto a un espacio de referencia } \\
\text { (por ejemplo, comarca, región, isla, país). El criterio sirve para identificar } \\
\text { accidentes geográficos excepcionales en un área. }\end{array}$ & $\begin{array}{l}0=>7 \\
0,25=5-7 \\
0,5=3-4 \\
0,75=1-2 \\
1=\text { único }\end{array}$ \\
\hline $\begin{array}{l}\text { Interés paleogeográfico (Ip) } \\
\text { Importancia del sitio para la historia de la Tierra o el clima (por ejemplo, } \\
\text { evolución del paisaje volcánico). }\end{array}$ & $\begin{array}{l}0=\text { Nulo } \\
0,25=\text { Débiles } \\
0,5=\text { Moderado } \\
0,75=\text { Alto } \\
1=\text { Muy alto }\end{array}$ \\
\hline Promedio & $(\mathrm{I}+\mathrm{R}+\mathrm{Rz}+\mathrm{Ip}) / 4$ \\
\hline
\end{tabular}


Tabla 2. Criterios utilizados para los valores adicionales o añadidos. Adaptado de Pereira et al. (2007); Reynard et al. (2007, 2016) y Bouzekraoui et al. (2017).

Table 2. Criteria used for the assessment of the additional values. Adapted from Pereira et al. (2007); Reynard et al. (2007, 2016), and Bouzekraoui et al. (2017).

\begin{tabular}{|c|c|c|}
\hline \multicolumn{3}{|r|}{ Valores ecológicos (Ec) } \\
\hline Criterio & & Valor cuantitativo \\
\hline $\begin{array}{l}\text { Influencia } \\
\text { ecológica }\end{array}$ & $\begin{array}{l}0 \\
0,25 \\
0,50 \\
0,75 \\
1\end{array}$ & $\begin{array}{l}\text { Sin relación con las características biológicas. } \\
\text { Presencia de flora y fauna interesante. } \\
\text { Uno de los mejores lugares para observar fauna y/o flora interesantes. } \\
\text { Las características geomorfológicas son importantes para los ecosistemas. } \\
\text { Las características geomorfológicas son cruciales para los ecosistemas. }\end{array}$ \\
\hline $\begin{array}{l}\text { Protección } \\
\text { del sitio }\end{array}$ & $\begin{array}{l}0 \\
0,25 \\
0,50 \\
0,75 \\
1\end{array}$ & $\begin{array}{l}\text { No protegido. } \\
\text { Protección a escala local. } \\
\text { Protección a escala regional. } \\
\text { Protección nacional. } \\
\text { Protección internacional. }\end{array}$ \\
\hline \multicolumn{3}{|r|}{ Valores estéticos (Es) } \\
\hline Criterio & & Valor cuantitativo \\
\hline $\begin{array}{l}\text { Puntos desde } \\
\text { donde se ven/ } \\
\text { visibilidad }\end{array}$ & $\begin{array}{l}0 \\
0,25 \\
0,50 \\
0,75 \\
1\end{array}$ & $\begin{array}{l}\text { El sitio solo es visible in situ o no es fácilmente accesible. } \\
\text { El sitio no es fácilmente accesible, pero ofrece } 1 \text { o } 2 \text { lugares desde donde se ve. } \\
\text { El sitio ofrece algunos puntos de vista (3-5) debido a la presencia de obstáculos visuales. } \\
\text { El sitio tiene muchos puntos de vista }(>5) \text {. } \\
\text { El sitio tiene muchos puntos de vista y es visible desde grandes distancias. }\end{array}$ \\
\hline $\begin{array}{l}\text { Contrastes } \\
\text { verticales } \\
\text { desarrollo y } \\
\text { estructuración } \\
\text { espacial }\end{array}$ & $\begin{array}{l}0 \\
0,25 \\
0,50 \\
0,75 \\
1\end{array}$ & $\begin{array}{l}\text { El sitio es monótono: topografía llana y monocolor. } \\
\text { El sitio muestra cierto desarrollo vertical y se reconocen hasta tres colores. } \\
\text { El sitio es abrupto y se reconocen hasta } 5 \text { colores. } \\
\text { El sitio muestra una topografía contrastada y se reconocen hasta } 7 \text { colores. } \\
\text { El sitio muestra una topografía contrastada y abrupta y se reconocen más de } 7 \text { colores. }\end{array}$ \\
\hline \multicolumn{3}{|r|}{ Valor cultural (C) } \\
\hline Criterio & & Valor cuantitativo \\
\hline $\begin{array}{l}\text { Importancia } \\
\text { religiosa y } \\
\text { simbólica }\end{array}$ & $\begin{array}{l}0 \\
0,25 \\
0,50 \\
0,75 \\
1\end{array}$ & $\begin{array}{l}\text { El sitio no presenta ninguna importancia religiosa. } \\
\text { El sitio presenta una importancia religiosa local. } \\
\text { El sitio presenta una importancia religiosa provincial o regional. } \\
\text { El sitio presenta una importancia religiosa nacional. } \\
\text { El sitio presenta importancia religiosa internacional. }\end{array}$ \\
\hline $\begin{array}{l}\text { Importancia } \\
\text { histórica }\end{array}$ & $\begin{array}{l}0 \\
0,25 \\
0,50 \\
0,75 \\
1\end{array}$ & $\begin{array}{l}\text { El sitio no presenta ninguna importancia histórica. } \\
\text { El sitio presenta una importancia histórica local. } \\
\text { El sitio presenta una importancia histórica provincial o regional. } \\
\text { El sitio presenta una importancia histórica nacional. } \\
\text { El sitio presenta una importancia histórica internacional. }\end{array}$ \\
\hline $\begin{array}{l}\text { Importancia } \\
\text { artística y } \\
\text { literaria }\end{array}$ & $\begin{array}{l}0 \\
0,25 \\
0,50 \\
0,75 \\
1\end{array}$ & $\begin{array}{l}\text { Ninguna importancia. } \\
\text { Importancia local. } \\
\text { Importancia regional. } \\
\text { Importancia nacional. } \\
\text { Importancia internacional. }\end{array}$ \\
\hline $\begin{array}{l}\text { Importancia } \\
\text { geohistórica }\end{array}$ & $\begin{array}{l}0 \\
0,25 \\
0,50 \\
0,75 \\
1\end{array}$ & $\begin{array}{l}\text { El sitio no está en el origen de ningún descubrimiento a través de la historia de las Ciencias de la Tierra. } \\
\text { El sitio, debido al desarrollo científico o la demostración de un proceso, es conocido localmente. } \\
\text { El sitio, debido al desarrollo científico o la demostración de un proceso, es conocido en el ámbito regional } \\
\text { y / o provincial. } \\
\text { El sitio, debido al desarrollo científico o la demostración de un proceso, es conocido a nivel nacional. } \\
\text { El sitio, debido al desarrollo científico o la demostración de un proceso, es conocido internacionalmente. }\end{array}$ \\
\hline \multicolumn{3}{|r|}{ Valores económicos $(\mathrm{E})$} \\
\hline Criterio & & Valor cuantitativo \\
\hline $\begin{array}{l}\text { Productos } \\
\text { económicos }\end{array}$ & $\begin{array}{l}0 \\
0,25 \\
0,50 \\
0,75 \\
1\end{array}$ & $\begin{array}{l}\text { El sitio no genera ningún ingreso. } \\
\text { El sitio es conocido, pero es la causa de beneficios indirectos (turismo). } \\
\text { El sitio es una fuente de ingresos, pero está amenazado por la actividad humana que puede agotarlo. } \\
\text { El sitio es administrado de manera sostenible, no causa ningún impacto. } \\
\text { El sitio permite la gestión directa de una empresa autónoma que no causa ningún impacto negativo. }\end{array}$ \\
\hline Promedio & & $(\mathbf{E c}+\mathbf{E s}+\mathrm{C}+\mathbf{E}) / 4$ \\
\hline
\end{tabular}


Los valores de uso y gestión se dividen entre los de protección y promoción. Dentro de los primeros, a su vez, se reconocen los de protección y daños-amenazas. Los de promoción se subdividen entre las condiciones de visita (accesibilidad, seguridad, contexto del sitio e infraestructuras turísticas) y los educativos (instalaciones interpretativas e interés educativo).

\section{Resultados y discusión}

\subsection{Identificación, inventario, selección y caracterización de los geomorfositios del PNT}

En total se han identificado e inventariado 23 geomorfositios potenciales en el PNT repartidos por las cuatro grandes unidades de paisaje definidas en el mismo. Estos son accesibles a través de la red de senderos del parque y representan la totalidad de las formas y procesos del relieve presentes en el PNT (Figura 3). Del total de geomorfositios identificados e inventariados se han seleccionado los diez que mejor representan la di- versidad volcánica del PNT (Tabla 3), pero también porque son los lugares más emblemáticos dentro del parque por su accesibilidad, afluencia de visitantes y por la imagen que proyectan del mismo. Dentro de los lugares seleccionados encontramos estratovolcanes, calderas, conos volcánicos, domos, cráteres, lagos de lava, campos de lavas, paredes rocosas, barrancos, llanos endorreicos, taludes, depósitos coluviales y aluviales, formas periglaciares, dunas, etc.

La geografía del PNT conforma el espacio volcánico más complejo de toda Canarias en relación con su carácter activo, la diversidad de mecanismos eruptivos, la heterogeneidad de materiales volcánicos y la variedad morfológica asociada al fenómeno eruptivo. A todo ello hay que sumar los matices introducidos por las diferentes edades entre unas construcciones eruptivas y otras, y el tiempo que han estado expuestas a los procesos de desmantelamiento. Además de las formas y procesos directamente vinculados con el volcanismo, debemos añadir las que son fruto de la erosión y de la acumulación asociadas con la dinámica de laderas, la escorrentía, el viento y el periglaciarismo (Figura 4).

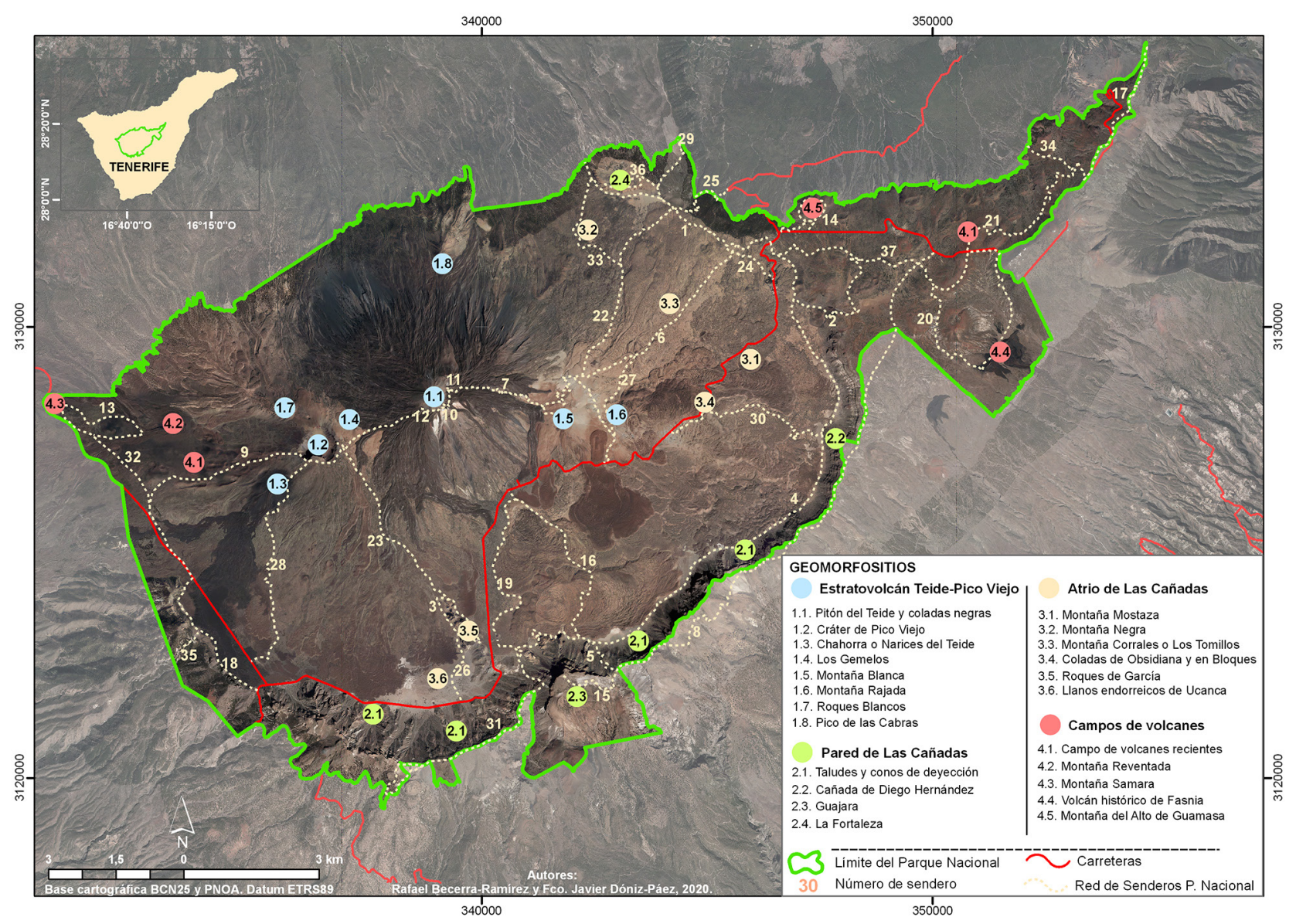

Figura 3. Mapa de localización de los geomorfositios identificados y seleccionados del PNT por unidad de paisaje.

Fuente: Elaboración propia a partir de la base cartográfica de Grafcan.

Figure 3. Location map of the identified and selected geomorphosites of TNP for landscape unit.

Source: Own elaboration from the cartographic base of Grafcan. 
Tabla 3. Geomorfositios seleccionados del PNT. Elaboración propia. Table 3. Geomorphosites selected in TNP. Own elaboration.

\begin{tabular}{|c|c|c|c|}
\hline $\mathbf{N}^{\mathbf{o}}$ & Geomorfositio & Unidad paisaje & Coordenadas \\
\hline 1 & Teide-Coladas Negras & \multirow{4}{*}{$\begin{array}{l}\text { Estratovolcán } \\
\text { Teide-Pico Viejo }\end{array}$} & $28^{\circ} 16^{\prime} 20^{\prime \prime} \mathrm{N} / 16^{\circ} 38^{\prime} 33^{\prime \prime} \mathrm{O}$ \\
\hline 2 & Cráter Pico Viejo & & $28^{\circ} 15^{\prime} 44^{\prime \prime} \mathrm{N} / 16^{\circ} 40^{\prime} 04^{\prime \prime} \mathrm{O}$ \\
\hline 3 & Montaña Blanca-Rajada & & $28^{\circ} 15^{\prime} 85^{\prime \prime} \mathrm{N} / 16^{\circ} 36^{\prime} 04^{\prime \prime} \mathrm{O}$ \\
\hline 4 & Chahorra-Narices Teide & & $28^{\circ} 15^{\prime} 13^{\prime \prime} \mathrm{N} / 16^{\circ} 40^{\prime} 42^{\prime \prime} \mathrm{O}$ \\
\hline 5 & Cañada Diego Hernández & \multirow{2}{*}{ Pared de Las Cañadas } & $28^{\circ} 16^{\prime} 49^{\prime \prime} \mathrm{N} / 16^{\circ} 33^{\prime} 08^{\prime \prime} \mathrm{O}$ \\
\hline 6 & Guajara & & $28^{\circ} 13^{\prime} 00^{\prime \prime} \mathrm{N} / 16^{\circ} 36^{\prime} 42^{\prime \prime} \mathrm{O}$ \\
\hline 7 & Roques de García & \multirow{2}{*}{ Atrio de Las Cañadas } & $28^{\circ} 13^{\prime} 23^{\prime \prime} \mathrm{N} / 16^{\circ} 37^{\prime} 51^{\prime \prime} \mathrm{O}$ \\
\hline 8 & Llanos de Ucanaca & & $28^{\circ} 12^{\prime} 40^{\prime \prime} \mathrm{N} / 16^{\circ} 38^{\prime} 06^{\prime \prime} \mathrm{O}$ \\
\hline 9 & M. Reventada-Samara & \multirow{2}{*}{$\begin{array}{l}\text { Campos de } \\
\text { volcanes-dorsales }\end{array}$} & $28^{\circ} 16^{\prime} 10^{\prime \prime} \mathrm{N} / 16^{\circ} 43^{\prime} 38^{\prime \prime} \mathrm{O}$ \\
\hline 10 & Volcán histórico de Fasnia & & $28^{\circ} 17^{\prime} 04^{\prime \prime} \mathrm{N} / 16^{\circ} 30^{\prime} 47^{\prime \prime} \mathrm{O}$ \\
\hline
\end{tabular}
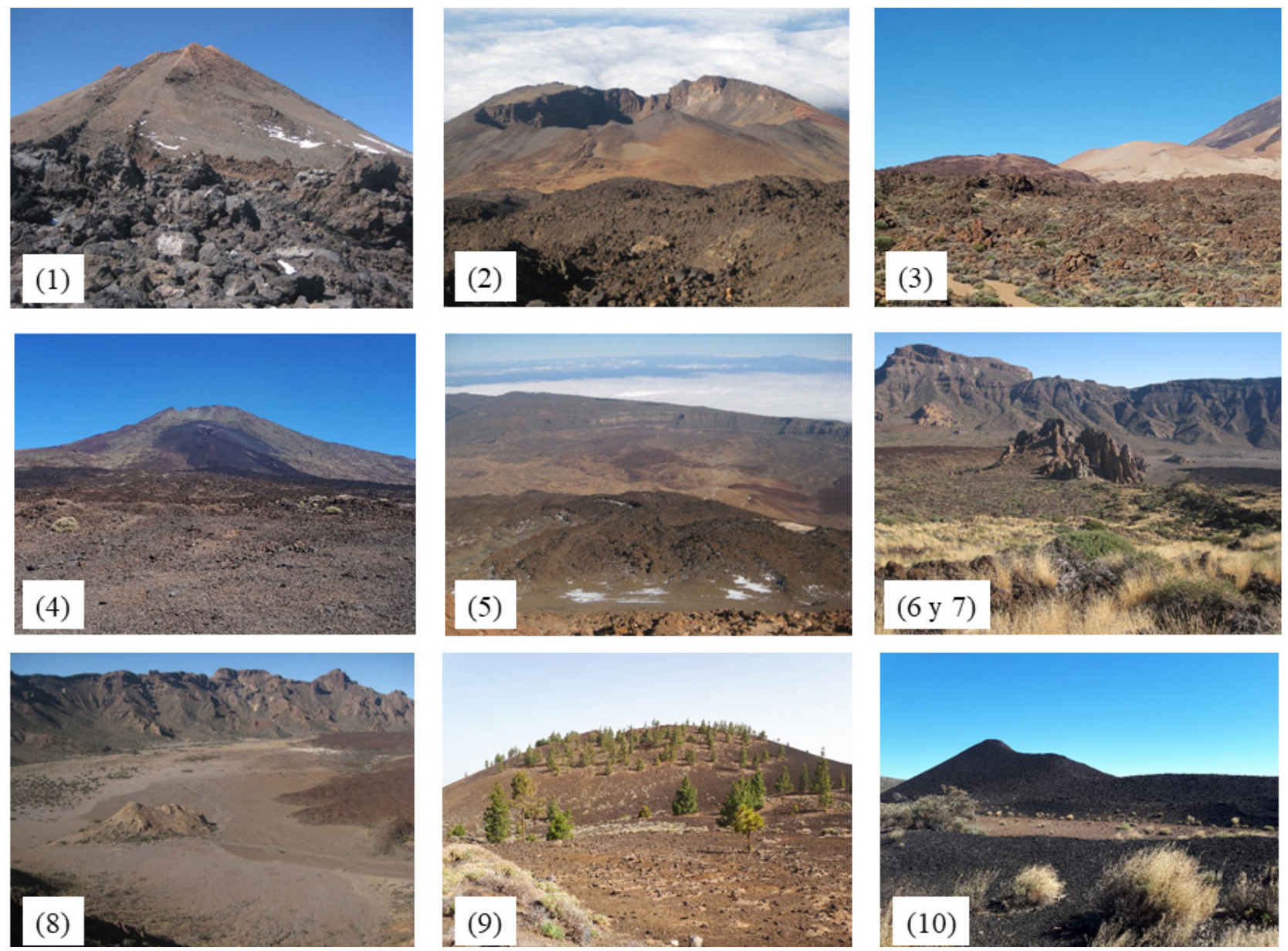

Figura 4. Geomorfositios seleccionados del PNT. La numeración corresponde a la tabla 3. (1) Cono terminal del Teide asociado a una erupción de edad medieval. (2) Cráter del estratovolcán de Pico Viejo en donde se alojaba el lago de lava. (3) Domos

subplinianos de Montaña Blanca y Rajada. (4) Erupción histórica de Narices del Teide de 1798. (5) Panorámica de la Caldera de Las Cañadas en el sector de Diego Hernández. (6) y (7) Roques de García y Montaña Guajara. (8) Área endorreica del Llano de Ucanca. 9 Volcán basáltico monogénico de Montaña Samara. 10 Volcán basáltico monogénico de Fasnia de la erupción de 1705.

Figure 4. Geomorphosites selected of TNP. The numbers are in the table 3. (1) Teide terminal cone associated with a medieval eruption. (2) Crater of the Pico Viejo stratovolcano where the lava lake was located. (3) Subplinian domes of Montaña Blanca and Rajada. (4) Historical eruption of Narices del Teide in 1798. (5) Panoramic view of the Caldera de Las Cañadas in the Diego Hernández sector. (6) and (7) Roques de García and Montaña Guajara. (8) Endorreic area of the Llano de Ucanca. 9 Cinder cone of Montaña Samara. 10 Basaltic monogenic volcano of Fasnia, 1705 eruption. 
En este sentido, las dinámicas eruptivas que se pueden reconocer dentro del parque varían desde las estrictamente hawaianas con la formación de lagos, charcas y fuentes de lava y la emisión de lavas muy fluidas de tipo pahoehoe y a a como en Pico Viejo o el volcán histórico de Fasnia, hasta las subplinianas de Montaña Blanca-Rajada con la construcción de domos-coladas, cumulodomos o edificios piroclásticos. La variedad de materiales se reconoce igualmente en el tipo de formas y van desde los basaltos propios de Narices del Teide, pasando por los traquibasaltos de Pico Viejo o La Pared de Las Cañadas, las traquifonolíticas de las Coladas Negras del Teide hasta las coladas fonolíticas de los domos de Montaña Rajada y sus lavas de obsidiana. Pero sin duda, es a través de la morfología volcánica, junto con los procesos de denudación, donde podemos apreciar mejor la geodiversidad del parque. Esta se resuelve a través de un complejo de formas donde el volcanismo es el fenómeno protagonista (calderas, estratovolcanes, domos, volcanes basálticos monogénicos, coneletes escoriáceos, hornitos, cráteres, fisuras efusivas, embudos de explosión, lagos de lava, campos de lava, bolas de acreción, tubos volcánicos, canales lávicos, arcos de empuje, mantos de pómez y lapilli, agujas de protusión, etc.), pero que han sido parcialmente retocadas por los procesos de erosión y acumulación (barrancos, suelos estriados, pipkrake, suelos poligonales, penitentes, dunas, debris flow, taludes, etc.). Sin embargo, en ocasiones son estas las que predominan como en los Llanos endorreicos de Ucanca o en los taludes detríticos de la Pared de Diego Hernández y Guajara. A todas estas geoformas actuales debemos añadir las heredadas asociadas con el periglaciarismo en el Teide o La Fortaleza en la Pared de Las Cañadas (Martín-Moreno, 2010). Igualmente, a estos valores geomorfológicos debemos sumarles los relacionados con una biogeografía excepcional, cuyos matorrales de retamas (Spartocytisus supranubius) y codesos (Adenocarpus viscosus) adaptados al estrés térmico de una alta montaña subtropical, entre otros, contribuyen a incrementar sus valores ecológicos. En la Tabla 4 se hace una síntesis de las principales geoformas que se pueden reconocer en cada uno de los diez geomorfositios seleccionados.

\subsection{Evaluación de los geomorfositios del PNT}

En las Tablas 5 y 6 se recogen las valoraciones científicas y añadidas de los diez geomorfositios seleccionados del PNT. En líneas generales, se puede observar que el promedio de los valores científicos $(0,62)$ está por encima de los añadidos $(0,44)$. Igualmente, la media de los valores científicos para cada uno de los sitios seleccionados es siempre superior a los adicionales. Al agrupar los valores intrínsecos de los geomorfositios según sean altos, medios o bajos, se aprecia que para los valores científicos el $50 \%$ son altos, el $30 \%$ medios y el $20 \%$ bajos; mientras que para los valores añadidos el 10\% son altos, el 50\% medios y el $40 \%$ bajos. Por tanto, los índices obtenidos parecen estar en total sintonía con la declaración del área de estudio como parque nacional y bien natural patrimonio de la humanidad, en donde hay un protagonismo casi absoluto de los aspectos naturales abióticos en la configuración de su paisaje frente a los culturales. La existencia de valores científicos bajos para los volcanes basálticos monogénicos recientes de Samara-Reventada y los volcanes históricos de Fasnia, están en relación con la menor geodiversidad de este tipo de volcanes por su reducido tamaño, la homogeneidad tanto de los materiales que los constituyen como de su dinámica eruptiva y su cronología. Además, su edad reciente e histórica y el ambiente frío donde se emplazan, está condicionado el escaso efecto

Tabla 4. Caracterización geomorfológica de los geomorfositios del PNT. Elaboración propia.

Table 4. Geomorphological characterization of the geomorphosites of TNP. Own elaboration.

\begin{tabular}{|c|l|l|}
\hline $\mathbf{N}^{\mathbf{0}}$ & \multicolumn{1}{|c|}{ Geomorfositio } & \multicolumn{1}{c|}{ Formas del relieve dominantes } \\
\hline 1 & Teide-coladas Negras & $\begin{array}{l}\text { Estratovolcán, domos, volcanes basálticos monogénicos, cráteres, coladas, bolas de acreción, } \\
\text { tubos volcánicos, barrancos, taludes de gravedad, formas periglaciares, penitentes. }\end{array}$ \\
\hline 2 & Cráter de Pico Viejo & $\begin{array}{l}\text { Estratovolcán, cráter, volcanes basálticos monogénicos, embudo explosivo, taludes, } \\
\text { barrancos, suelos estriados y poligonales. }\end{array}$ \\
\hline 3 & M. Blanca-Rajada & $\begin{array}{l}\text { Estratovolcán incipiente, cumulodomos, domos-colada, cráteres, coladas en bloques, } \\
\text { agujas protusión, solifluxión. }\end{array}$ \\
\hline 4 & Chahorra-Narices Teide & $\begin{array}{l}\text { Volcán basáltico monogénico, coneletes escoriáceos, cráteres, embudos de explosión, } \\
\text { coladas de lava, taludes, periglaciarismo. }\end{array}$ \\
\hline 5 & Cañada Diego Hernández & Caldera, paredes rocosas, coladas, diques, barrancos, taludes. \\
\hline 6 & Guajara & Coladas, barrancos, taludes. \\
\hline 7 & Roques de García & Coladas, cascadas de lava, diques, taludes. \\
\hline 8 & Llanos de Ucanca & $\begin{array}{l}\text { Coladas, barrancos, aluviones, llanos endorreicos, taludes, formas periglaciares, nebkhas, } \\
\text { dunas trepadoras. }\end{array}$ \\
\hline 9 & M. Reventada-Samara & $\begin{array}{l}\text { Volcán basáltico monogénico, cráteres, embudos de explosión, fisuras efusivas, lavas } \\
\text { pahoehoe y aa, mezcla de magmas, taludes. }\end{array}$ \\
\hline 10 & Volcán histórico de Fasnia & $\begin{array}{l}\text { Volcanes basálticos monogénicos, coneletes escoriáceos, hornitos, cráteres, embudos de } \\
\text { explosión, fisuras efusivas, fuentes de lava, lavas pahoehoe, aa, barrancos, taludes. }\end{array}$ \\
\hline
\end{tabular}


Tabla 5. Evaluación de los valores científicos de los geomorfositios del PNT. Elaboración propia.

Table 5. Assessment of the scientific values of geomorphosites in TNP. Own elaboration.

\begin{tabular}{|l|c|c|c|c|c|c|}
\hline \multicolumn{7}{|c|}{ Valores científicos de los geomorfositios del PNT } \\
\hline \multicolumn{1}{|c|}{ Geomorfositio } & Integridad & Representatividad & Rareza & Paleografía & Promedio & Ranking \\
\hline Volcán Teide & 1 & 1 & 1 & 0,75 & 0,94 & 1 \\
\hline Cráter de Pico Viejo & 1 & 1 & 1 & 0,50 & 0,88 & 2 \\
\hline Diego Hernández & 1 & 0,75 & 0,75 & 0,75 & 0,81 & 3 \\
\hline M. Blanca-Rajada & 1 & 0,75 & 0,50 & 0,50 & 0,69 & 4 \\
\hline Llanos de Ucanca & 0,75 & 0,75 & 0,25 & 0,75 & 0,63 & 5 \\
\hline Guajara & 1 & 0,50 & 0,50 & 0,75 & 0,56 & 6 \\
\hline Narices del Teide & 1 & 0,50 & 0,25 & 0,25 & 0,50 & 7 \\
\hline Roques de García & 0,50 & 0,25 & 0,50 & 0,50 & 0,44 & 8 \\
\hline Samara-Reventada & 0,50 & 0,25 & 0,50 & 0,25 & 0,38 & 9 \\
\hline Volcanes Fasnia & 0,50 & 0,25 & 0,50 & 0,25 & 0,38 & 10 \\
\hline Promedios & 0,83 & 0,61 & 0,58 & 0,53 & 0,62 & - \\
\hline
\end{tabular}

Tabla 6. Evaluación de los valores adicionales de los geomorfositios del PNT. Elaboración propia.

Table 6. Assessment of the additional values of geomorphosites in TNP. Own elaboration.

\begin{tabular}{|l|c|c|c|c|c|c|}
\hline \multicolumn{7}{|c|}{ Valores adicionales o añadidos de los geomorfositios del PNT } \\
\hline \multicolumn{1}{|c|}{ Geomorfositio } & Ecológicos & Estéticos & Culturales & Económicos & Promedio & Ranking \\
\hline Volcán Teide & 0,88 & 1 & 0,69 & 0,25 & 0,70 & 1 \\
\hline Llanos de Ucanca & 0,88 & 0,50 & 0,31 & 0,25 & 0,48 & 2 \\
\hline Guajara & 0,63 & 0,63 & 0,38 & 0,25 & 0,47 & 3 \\
\hline Diego Hernández & 0,63 & 0,63 & 0,31 & 0,25 & 0,45 & 4 \\
\hline Cráter de Pico Viejo & 0,63 & 0,50 & 0,38 & 0,25 & 0,44 & 5 \\
\hline Roques de García & 0,63 & 0,50 & 0,25 & 0,25 & 0,41 & 6 \\
\hline Volcanes Fasnia & 0,63 & 0,38 & 0,50 & 0,25 & 0,39 & 7 \\
\hline Narices del Teide & 0,63 & 0,25 & 0,31 & 0,25 & 0,36 & 8 \\
\hline M. Blanca-Rajada & 0,63 & 0,38 & 0,11 & 0,25 & 0,34 & 9 \\
\hline Samara-Reventada & 0,75 & 0,25 & 0,06 & 0,25 & 0,33 & 10 \\
\hline Promedios & 0,69 & 0,50 & 0,31 & 0,25 & 0,44 & - \\
\hline
\end{tabular}

de los procesos de desmantelamiento y, por ende, de las formas derivadas sobre sus conos volcánicos, campos de lapilli y corrientes lávicas.

Con respecto a la posición que ocupan los geomorfositios en función de la media de sus valores intrínsecos, se ve que sólo el estratovolcán Teide ocupa el primer lugar en ambas valoraciones, coincidiendo en este las puntuaciones más altas de los valores científicos $(0,94)$ y añadidos $(0,70)$. Esto evidencia la importancia natural del estratovolcán Teide, que prácticamente reúne toda la diversidad de formas y procesos del relieve identificados en el interior del parque nacional; pero también a su importante papel como referente cultural a lo largo del tiempo, desde la religión de los guanches, icono para los viajeros y científicos hasta referente musical, literario y gastronómico para los canarios. Ahora bien, es llamativo que lugares con puntuaciones científicas altas, luego no se posicionen de manera similar en el ranking de las valoraciones adicionales (cráter de Pico Viejo), lo cual puede responder a que, aun siendo un lugar muy geodiverso y contar con el cráter volcánico más grande de Tenerife ( $>0,8 \mathrm{~km}$ de diámetro) que albergó en su interior el lago de lava, también más importante de la isla, históricamente ha sido más inaccesible y ha estado a la sombra del cercano Teide. A su vez, hay geomorfositios (como Los Llanos de Ucanca) cuyos índices culturales son altos y los científicos medios. Estos últimos están en relación con la importancia que han tenido las zonas topográficas más bajas y llanas del PNT, en donde se han acumulado los sedimentos a lo largo de miles de años y en donde de manera estacional pueden encharcarse. Estos hechos favorecen que prospere la cubierta vegetal y se convirtiesen en los lugares preferidos para la ocupación humana desarrollando actividades como el pastoreo desde época guanche 
casi hasta la actualidad o las actividades de extracción de tierras o la apicultura.

Al correlacionar los valores científicos con los adicionales (Figura 5) los geomorfositios se agrupan en tres categorías. En la primera estarían los que poseen elevados valores científicos y adicionales que es la que menor número de lugares acogen con tan solo uno (Teide y las Coladas Negras). A la segunda pertenecen los geomorfositios que poseen elevados valores científicos y valores añadidos medios, sumando el $40 \%$ de los lugares seleccionados (cráter de Pico Viejo, Montaña Blanca-Rajada, Cañada de Diego Hernández y Llanos Ucanca). Por último, está la tercera categoría, que es la más numerosa con el $50 \%$ y que son los geomorfositios que cuentan con valores científicos y adicionales medios (Chahorra-Narices del Teide, Guajara, Roques de García, Montaña Reventada-Samara y volcán histórico de Fasnia).

En relación con los valores de uso y gestión es necesario hacer algunas consideraciones, máxime cuando estos valores están referidos a aspectos como la protección y promoción del lugar, que sí son claves dentro del uso turístico de los sitios seleccionados. En este sentido, en relación con la protección es necesario señalar que los diez geomorfositios están bajo la figura de parque nacional y, además, algunos de ellos cuentan con otras protecciones como las de monumento natural (Teide, Pico Viejo, Montaña Blanca-Rajada, Narices del Teide) o están dentro de la Red Natura 2000, como zonas de especial conservación (ZEC) o como zonas especiales para la protección de aves (ZEPA).

Las principales amenazas en el PNT están derivadas de la masiva afluencia de turistas (Figura 6) y de los equipamientos e infraestructuras que se han instalado para ello. Esto ha motivado que, en reiteradas ocasiones, se discuta sobre la idea de aplicar medidas para reducir el número total de visitantes y descongestionar la presión turística sobre determinados geomorfositios como el Teide o los Roques de García (Dóniz-Páez, 2010).

En cuanto a los valores de uso y gestión referidos a la promoción (visitas y educativos) el PNT está muy avanzado. Ha contribuido a ello la gran afluencia de visitantes anuales (Figura 6) que ha requerido grandes inversiones en equipamientos e infraestructuras de acceso, seguridad y turísticas en el interior del parque y que todavía pueden mejorarse para una adecuada adaptación a la demanda y a los criterios de sostenibilidad (centros de interpretación, restaurantes, red de senderos, teleférico, parador nacional, transporte público, aparcamientos, etc.). No podemos obviar algunos de los productos turísticos que se están desarrollando ya en el parque como la observación de estrellas o el senderismo. Al margen de los aspectos turísticos, una de las principales actividades de uso público del parque son las educativas, para ello cuenta con tres centros de interpretación del patrimonio en el interior del PNT (Portillo, Cañada Blanca y el museo etnográfico Juan Évora) más uno en el casco urbano de La Orotava (Telesforo Bravo) y visitas guiadas fundamentalmente orientadas para escolares de distintos niveles educativos, pero también para los turistas todos los días del año.

\subsection{Volcano turismo en el Parque Nacional del Teide}

La diversidad de paisajes volcánicos inventariados a través de los diez geomorfositios seleccionados y valorados en este trabajo constituye el principal atractivo para el visitante (Figura 7). Sin embargo, y a pesar de las conti-

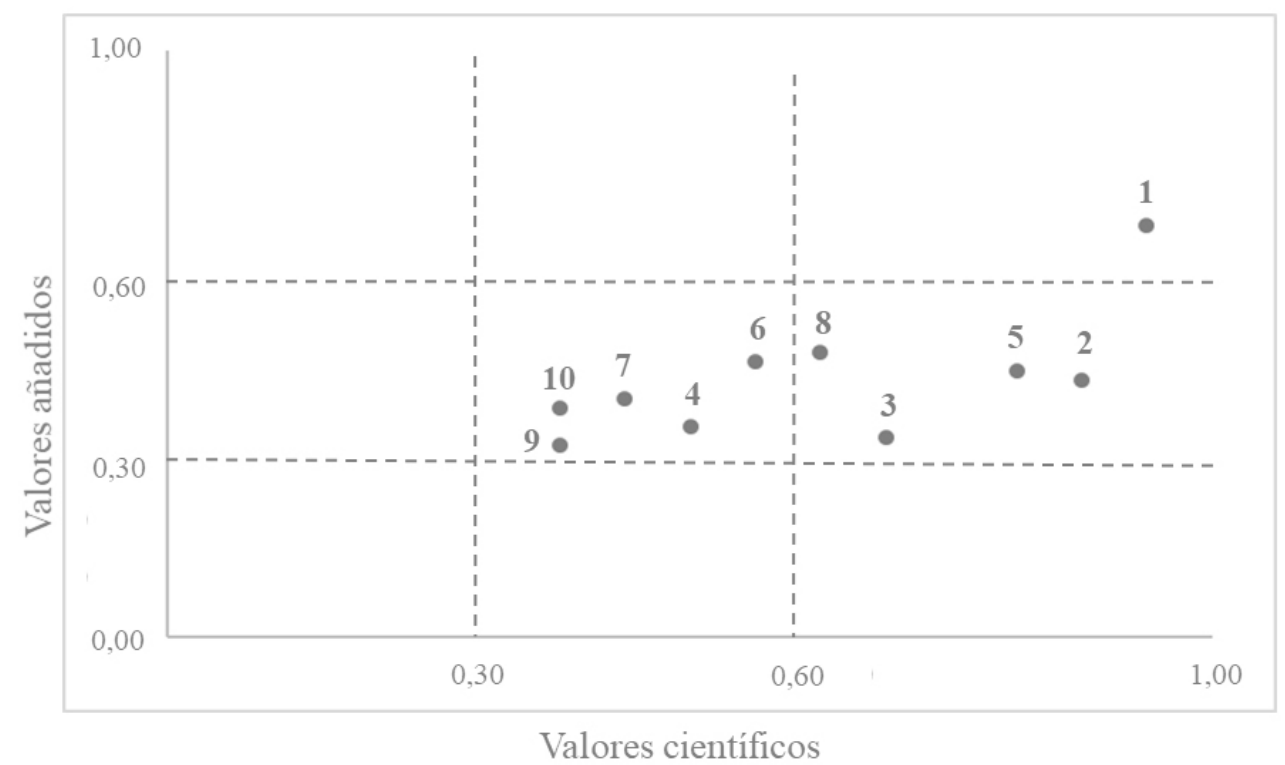

Figura 5. Relación entre los valores científicos y añadidos para los geomorfositios seleccionados del PNT. La numeración corresponde a la tabla 3. Elaboración propia. Figure 5. Relationship between scientific values and additional values of geomorphosites of TNP. Numbers are refered to table 3. Own elaboration. 


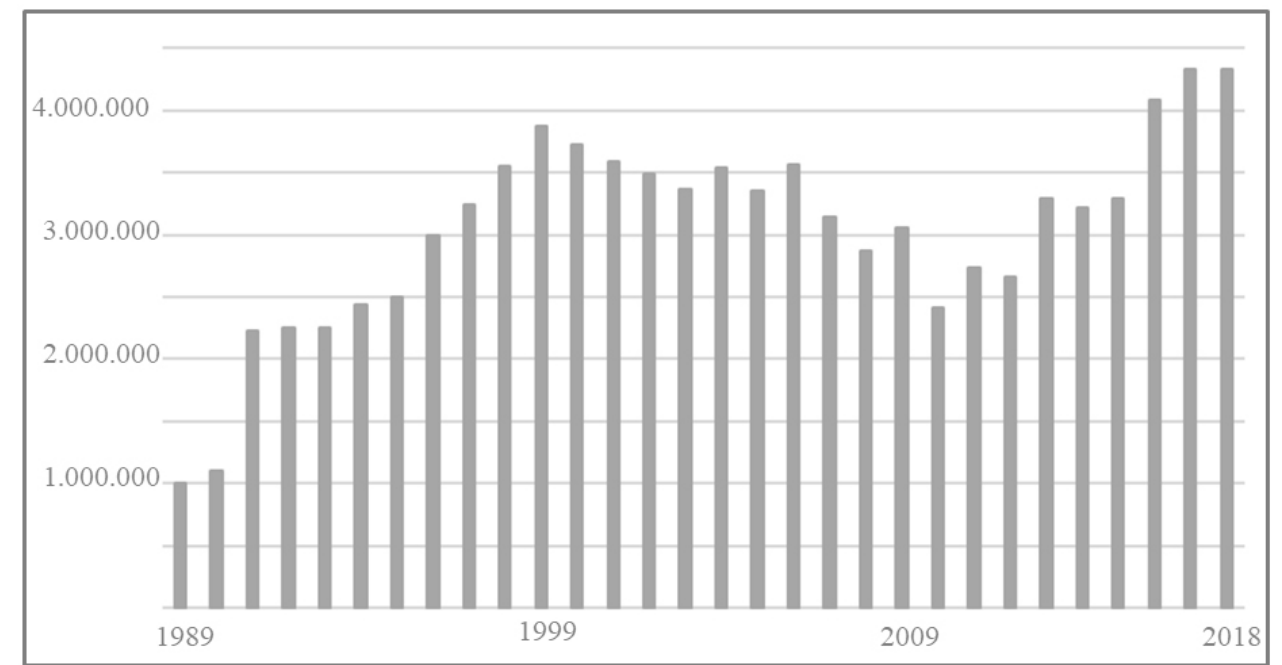

Figura 6. Evolución de los visitantes en PNT. Fuente Istac 2020. Elaboración propia.

Figure 6. Evolution of the visitors in PNT. Source: Istac 2020. Own elaboration.
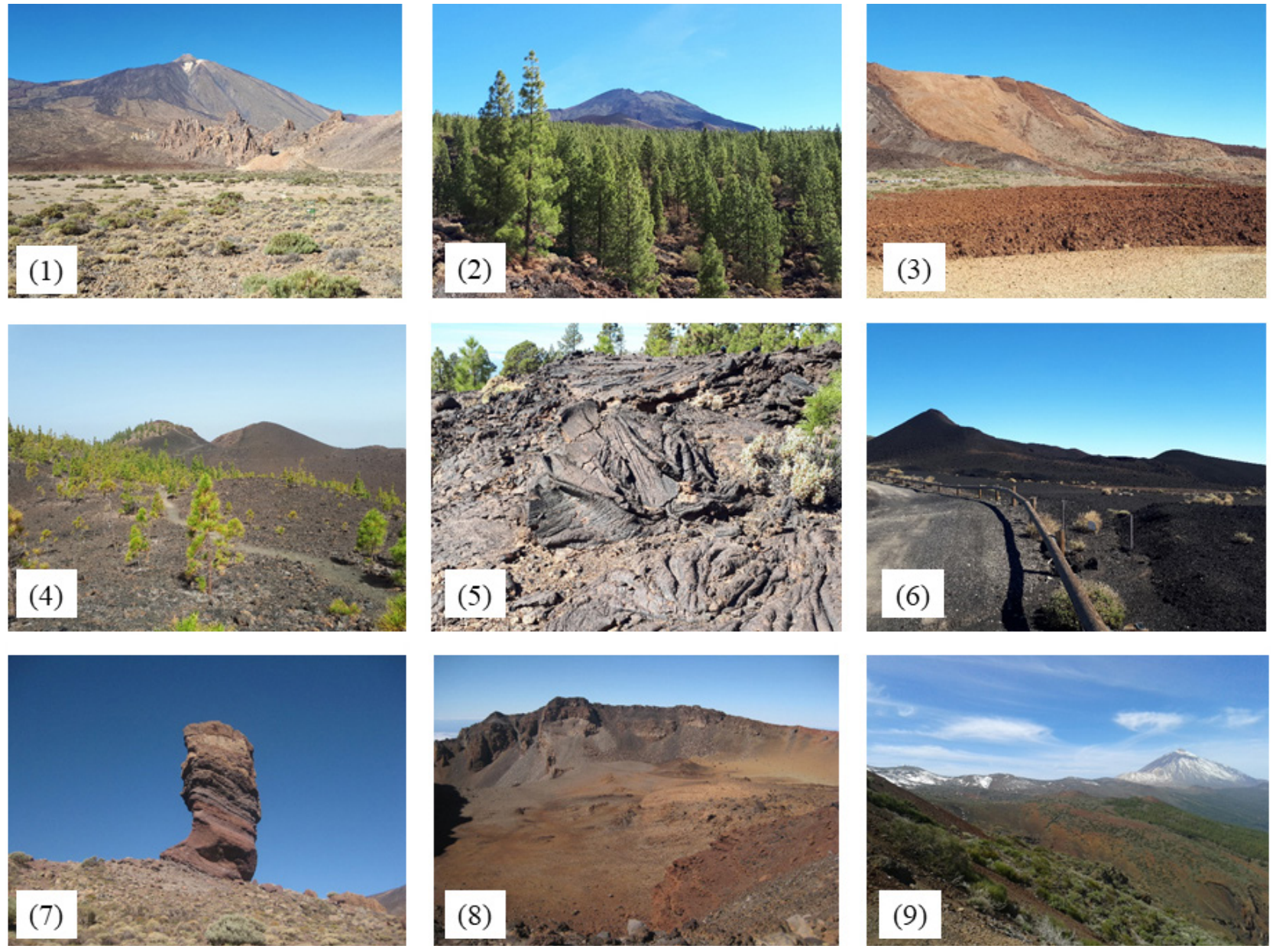

Figura 7. Paisajes volcánicos del PNT. (1) Estratovolcán del Teide. (2) Estratovolcán de Pico Viejo y erupción de Chahorra.

(3) Domo de Montaña Blanca. (4) Volcán basáltico monogénico de Montaña Samara. (5) Lavas pahoehoe de Montaña Reventada.

(6) Volcán histórico de Fasnia. (7) Forma erosiva de Roque Cinchado. (8) Cráter de Pico Viejo. (9) panorámica del PNT.

Figure 7. Volcanic landscapes of TNP. (1) Teide stratovolcano. (2) Pico Viejo stratovolcano and Chahora historical eruption.

(3) Montaña Blanca lava dome. (4) Montaña Samara cinder cones. (5) Pahoehoe lava flows from Montaña Reventada. (6) Fasnia cinder cone. (7) Erosion form of Roque Cinchado. (8) Crater of Pico Viejo. (9) General view of TNP. 
nuas visitas guiadas por los responsables del PNT, en muchas ocasiones ni los turistas ni los propios gestores del parque son conscientes de cuáles son los recursos volcánicos que conforman esa variedad paisajística con elevados valores estéticos y escénicos que están consumiendo unos y ofertando otros (Dóniz-Páez, 2010; Dóniz-Páez \& Becerra-Ramírez, 2019). En este sentido, las experiencias en otras regiones volcánicas ponen de manifiesto que las principales motivaciones y atracciones son diversas y van desde la búsqueda de relax, el hecho novedoso de visitar un volcán, el paisaje, el conocimiento sobre el fenómeno eruptivo, la socialización con otros visitantes, los aspectos religiosos, la salud, la búsqueda de productos alternativos, los desastres vinculados con las erupciones o el patrimonio natural y cultural de los volcanes basados en sus atributos geológicos (Heggie, 2009; Dowling, 2013; Davis et al., 2013; Wang et al., 2014; Różycka \& Migoń, 2018; Aquino et al., 2019; Mateo et al., 2019; Suhud \& Allan, 2019). Dentro de la variedad de recursos del volcano turismo estos se pueden agrupar en torno a ocho tipos de atractivos diferentes que sintetizan perfectamente la diversidad del patrimonio natural y cultural asociado al fenómeno volcánico (Sigurdsson \& Lopes, 2000; DónizPáez, 2012; Becerra-Ramírez et al., 2017; Tabla 7). Desde sus paisajes caracterizados por una gran diversidad de formas y colores y con un elevado contenido estético y escénico, pasando por el espectáculo de las erupciones de los volcanes rojos o grises (de los que hay evidencias en el PNT), las manifestaciones termales que indican el carácter más o menos activo de los volcanes, la biodiversidad y las actividades ecoturísticas, los contrastes topográficos y la práctica de deportes de aventura y riesgo o el senderismo, las playas singulares de color negro o rojo, la arqueología y la religión asociadas a la ocupación de estos territorios y su explicación mágico-religiosa en muchas ocasiones vinculadas con su carácter activo, hasta los diferentes usos que han configurado la cultura del volcán.

De todos los recursos y/o atractivos descritos para el turismo volcánico en el PNT se pueden reconocer casi todos a excepción de las erupciones y las playas (DónizPáez \& Becerra-Ramírez, 2019); sin embargo, los volcanes del parque muestran actividad como lo ponen de manifiesto las fumaloras de La Rambleta y del cráter del Teide dentro del geomorfositio número uno y las playas se pueden apreciar desde las cumbres de Tenerife, aunque no sean un recurso propio del PNT. En este sentido, los diez geomorfositios estudiados en este trabajo acogen la inmensa mayoría de atractivos definidos en la literatura científica para del turismo volcánico tal y como se refleja en la Tabla 7.

\section{Consideraciones finales y recomendaciones}

En este trabajo se han identificado, inventariado, seleccionado, caracterizado y valorado diez geomorfositios volcánicos del Parque Nacional del Teide, siguiendo una metodología semicuantitativa previamente aplicada con éxito
Tabla 7. Atractivos del volcano turismo en los geomorfositios del PNT: 1. Paisajes; 2. Erupciones; 3. Termalismo;

4. Ecoturismo; 5. Deportes; 6. Playas; 7. Arqueología-cultural; y 8. Religión. Elaboración propia.

Table 7. Attractions for volcano tourism in TNP:

1. Landscapes; 2. Eruptions; 3. Hot springs; 4. Ecotourism;

5. Sports; 6. Beaches; 7. Archeology-cultural heritage;

8. Religion. Own elaboration.

\begin{tabular}{|l|l|l|l|l|l|l|l|l|}
\hline \multicolumn{1}{|c|}{ Geomorfositio } & $\mathbf{1}$ & $\mathbf{2}$ & $\mathbf{3}$ & $\mathbf{4}$ & $\mathbf{5}$ & $\mathbf{6}$ & $\mathbf{7}$ & $\mathbf{8}$ \\
\hline Teide-Coladas Negras & & & & & & & & \\
\hline Cráter de Pico Viejo & & & & & & & & \\
\hline Montaña Blanca-Rajada & & & & & & & & \\
\hline Chahora-Narices del Teide & & & & & & & & \\
\hline Cañada de Diego Hernández & & & & & & & & \\
\hline Montaña de Guajara & & & & & & & & \\
\hline Roques de García & & & & & & & & \\
\hline Llanos Ucanca & & & & & & & & \\
\hline Montaña Reventada-Samara & & & & & & & & \\
\hline Volcán histórico de Fasnia & & & & & & & & \\
\hline
\end{tabular}

en otros espacios naturales protegidos de naturaleza volcánica y adaptada para los fines de este estudio. El PNT es el espacio protegido más visitado de España con una media de más de tres millones de visitantes anuales que se ven atraídos por los espectaculares paisajes de una alta montaña volcánica subtropical. A pesar de esta masiva afluencia, hasta ahora no se había aplicado la metodología de valoración del patrimonio geomorfológico con el fin de determinar el interés geoturístico y volcano turístico de espacios concretos del parque. Dados los importantes valores naturales y culturales del PNT, en este trabajo se ha apostado por una aproximación más geográfica, holística e integral del geoturismo y del volcano turismo, donde los sitios seleccionados deben sintetizar toda esa diversidad patrimonial a través de su valoración científica (integridad, representatividad, rareza e interés paleogeográfico), adicional (ecológicos, estéticos, culturales y económicos) y de uso y gestión (protección y promoción).

Los geomorfositios estudiados son los más representativos de la naturaleza volcánica del parque y son accesibles para los visitantes a través de la red de senderos con la que cuenta el PNT. En líneas generales los valores científicos están por encima de los añadidos tanto para el conjunto de los geomorfositios estudiados como para cada uno de los diez por separado. Estos datos están acordes con la inclusión de los lugares evaluados dentro del parque nacional, que a su vez es patrimonio mundial de la Unesco, zona especial para la protección de las aves o zonas de especial conservación.

Sin duda, la propuesta de esta investigación tiene un marcado carácter aplicado y tanto los gestores del parque como las diversas empresas de ocio alternativo que acceden al mismo cuentan con un documento en el que se hace una selección de los geomorfositios donde se enfatiza la relación de estos con el conocimiento de las 
ciencias de la Tierra, acordes con la premisa de que para conservar algo debemos valorarlo y conocerlo. Por tanto, los lugares seleccionados y estudiados pueden sustentar sus propuestas de creación de nuevos productos y experiencias geoturísticas llenándolas de contenido y que vayan más allá de la simple observación estética de los valores geológicos y geomorfológicos de los paisajes del PNT.

Por lo tanto, aunque esta metodología se ha mostrado válida para identificar, inventariar, seleccionar y valorar geomorfositios con potencial geoturístico, aún queda bastante para lograr una metodología definitiva sobre la valoración de lugares de interés geomorfológico atendiendo a un objetivo específico, como es en este caso el volcano turismo. Por ello, es necesario seguir investigando en metodologías que afinen el proceso de identificación, inventario y selección de los geomorfositios con el fin de ir configurando un catálogo cada vez más amplio de lugares de interés para el volcano turismo; pero también métodos que mejoren la valoración de los lugares desde la perspectiva más geográfica del concepto de geoturismo volcánico, para poder integrar el patrimonio natural y cultural en la misma.

\section{Agradecimientos}

Este trabajo ha sido posible gracias al proyecto "VOLTURMAC, Fortalecimiento del volcano turismo en la Macaronesia (MAC2/4.6c/298)", que co-financia el Programa de Cooperación INTERREG V-A España-Portugal MAC (Madeira-Azores-Canarias) 2014-2020. Los autores quieren agradecer los comentarios, sugerencias y reflexiones de los dos revisores anónimos que, sin duda, han contribuido a mejorar la versión final del trabajo.

\section{Referencias}

Ablay, G. \& Martí, J., 2000. Stratigraphy, structure, and volcanic evolution of the Pico Teide-Pico Viejo formation, Tenerife, Canary Islands. Journal Volcanology Geothermal Research, 103: 175-208. http://doi.org/10.1016/S0377-0273(00)00224-9

Aquino, R.S., Schänzel, H.A. \& Hyde, K.F., 2019. Analysing push and pull motives for volcano tourism at Mount Pinatubo, Philippines. Geoheritage, 11: 177-191. http://doi. org/10.1007/s12371-017-0254-Z

Arechavaleta, M. \& Oromí, P., 2004. Fauna invertebrada. En: AA.VV. Parque Nacional del Teide. Ed. Esfagnos-MMA, Madrid, pp. 143-170.

Arnay de la Rosa, M., 2004. Arqueología. En: AA.VV. Parque Nacional del Teide. Ed. Esfagnos-MMA, Madrid, pp. 199-212.

Arouca Declaration, 2011. International Congress of Geotourism, Geopark Arouca, Portugal. Recuperado de http://www. europeangeoparks.org/? $\mathrm{p}=223$.

Becerra-Ramírez, R., 2013. Geomorfología y Geopatrimonio de los volcanes magmáticos de la Región Volcánica del Campo de Calatrava. Tesis Doctoral inédita. Universidad de Castilla-La Mancha, 822 pp., Ciudad Real. https://ruidera.uclm. es/xmlui/handle/10578/3606.

Becerra-Ramírez, R., Escobar, E., González, E., Dóniz-Páez, J. \& Becerra-Ramírez, M.C., 2017. Recursos para el geoturismo en la región volcánica de Campo de Calatrava (Ciudad Real, España Central). En: Carcavilla, L., Duque-Macías, J., Giménez, J., Hilario, A., Monge-Ganuzas, M., Vegas, J. \& Rodríguez, A. (eds.). Patrimonio geológico, gestionando la parte abiótica del patrimonio natural. Instituto Geológico y Minero de España, Madrid, pp. 309-314.

Bouzekraoui, H., Barakat, A., Touhami, F., Mouaddine, A. \& El Youssi, M., 2017. Inventory and assessment of geomorphosites for geotourism development: A case study of Ait Bou Oulli valley (Central High-Atlas, Morocco). Area, 50: 331-343. https://doi.org/10.1111/area.12380

Carracedo, J., 2006. El volcán Teide. Volcanología, interpretación de paisajes e itinerarios comentados. Cajacanarias. Santa Cruz de Tenerife, $431 \mathrm{pp}$.

Carracedo, J. \& Troll, V., 2013. From Myth to Science: The Contribution of Mount Teideto the Advancement of Volcanology. En: Carracedo, J. \& Troll, V. (Eds.). Teide Volcano, Geology and Eruptions of a Highly Differentiated Oceanic Stratovolcano. Springer Heidelberg, New York Dordrecht London, pp.1-21.

Carcavilla, L., Belmonte, A., Durán, J. \& Hilario, A., 2011. Geoturismo: concepto y perspectivas en España. Enseñanza de las Ciencias de la Tierra, 19(1): 81-94.

Chen, A., Lu, Y. \& Ng. Y., 2015. Principles of geotourism. Springer-Verlag Berlin Heidelberg, Berlin.

Chen, A., Ng, Y., Zhang, E. \& Tin, M., 2020. Dictionary of geotourism. Springer Singapore, pp., 732.

Davis S., Anshuka AK., Duley S., Huff M. \& Logan, C., 2013. Managing risk and allure at volcanoes in Hawaii: how close is too close. GeoJournal of Tourism and Geosites, 12(2): 85-93.

Dóniz-Páez, J., 2010. Turismo en Espacios Naturales Protegidos en Canarias: el Parque Nacional de Las Cañadas del Teide (Tenerife, España), durante el periodo 2000-2008. Estudios Turísticos, 183: 91-103.

Dóniz-Páez, J., 2012. Turismo Volcánico. Canarias: Productos turísticos y propuesta de itinerarios volcánicos. Editorial Académica Alemana, 115 pp., Madrid.

Dóniz-Páez, J., 2014. Reflexiones en torno al turismo volcánico. El caso de las Islas Canarias, España. Pasos, 12(2): 467-478.

Dóniz-Páez, J. \& Becerra-Ramírez, R., 2019. Geoturismo volcánico en el Parque Nacional de Las Cañadas del Teide (Tenerife, Canarias, España). Bloc de las Islas CanariasFundación Añazo Nova, 9: 99-109.

Dóniz-Páez, J., Becerra-Ramírez, R., González, E., Guillén, C. \& Escobar, E., 2011. Geomorphosites and geotourism in volcanic landscape: the example of La Corona del Lajial cinder cones (El Hierro, Canary Islands, Spain). GeoJournal of Tourism and Geosites, 2(8): 185-197.

Dóniz-Páez, J., Hernández, W., Przeor, M. \& Pérez, N., 2019. Guía geoturística de Tenerife. Involcan, pp., 113, S/C Tenerife.

Dowling, R., 2013. Global geotourism: An emerging form of sustainable tourism. Czech Journal of Tourism, 2(2): 59-79. https://doi.org/10.2478/cjot-2013-0004

Dowling R. \& Newsome, D., 2018. Geotourism: definition, characteristics and international perspectives. En: Dowling R. \& Newsome, D. (Eds.). Handbook of Geotourism. Edward Elgar, Cheltenham, pp. 1-22.

Erfurt-Cooper, P., 2014. Volcanic Tourist Destinations. Geoheritage. Geoparks and Geotourism Series. Springer Verlag, Berlin, Heidelberg, pp., 384, Berlin.

Erfurt-Cooper P., 2018. Geotourism development and management in volcanic regions. En: Dowling R. \& Newsome, D. (Eds). Handbook of Geotourism. Edward Elgar, Cheltenham, pp. 152-167.

Erfurt-Cooper, P. \& Cooper, M., 2010. Volcano and geothermal tourism. Sustanible geo-resoruces for leisur and recreation. Publisher: Earthscan Publications, pp., 378, London. 
Erfurt-Cooper, P., Sigurdsson, H. \& Lopes, R., 2015. Volcanoes and Tourism. En: Sigurdsson, H., Rymer, H., Stix, J. \& McNut, S. (Eds.). The encyclopedia of volcanoes. Elsevier, Academic Press, London, pp. 1295-1311.

Gebauer, A., 2014. Alexander von Humboldt. Su semana en Tenerife. 1799. Zech, pp., 205, Santa Úrsula.

González, M., Serrano, E. \& González, M., 2014. Lugares de interés geomorfológico, geopatrimonio y gestión de espacios naturales protegidos: el Parque Natural de Valderejo (Alava, España). Revista de Geografía Norte Grande, 59: 45-64.

González-Lemus, N. \& Sánchez, I., 2004. El Teide, de mito geográfico a Parque Nacional. Nivaria ediciones, La Laguna.

Heggie, T., 2009. Geotourism and volcanoes: Health hazards facing tourists at volcanic and geothermal destinations. Travel Medicine and Infectious Disease, 7: 257-261. http:// doi.org/10.1016/j.tmaid.2009.06.002

Hernández-González, M., 2005. Alexander von Humboldt. Permanencia en Tenerife. Ediciones Idea, pp., 326, S/C Tenerife.

Hose A., 1995. Selling the story of Britain's stone. Environmental Interpretation, 10(2): 16-17.

Hose, A., 2008. Towards a history of geotourism: definitions, antecedents and the future. Geological Society, London, 501 Special Publications, 300(1): 37-6. http://doi.org/10.1144/ SP300.5

Istac, 2020. Recuperado de: http://www.gobiernodecanarias. org/istac/

Joyce, B., 2009. Geomorphosites and volcanism. En: Reynard E., Coratza P. \& Regolini-Bissig G. (Eds). Geomorphosites. Verlag Dr. Friedrich Pfeil, Munchen, pp. 175-188.

Kubalíková, L., 2013. Geomorphosite assessment for geotourism purposes. Czech Journal of Tourism, 2(2): 80-104. https://doi.org/10.2478/cjot-2013-0005

Kubalíková, L., 2019. Assessing Geotourism Resources on a Local Level: A Case Study from Southern Moravia (Czech Republic). Resources, 8: 150. http://doi.org/10.3390/resources 8030150

Machado, A., 2004. Fauna vertebrada. En: AA.VV. Parque Nacional del Teide. Ed. Esfagnos-MMA, Madrid, pp. 171-198.

Martí, J., Mitjavila, J. \& Araña, V., 1994. Stratigraphy, structure and geochronology of the Las Cañadas Caldera (Tenerife, Canary Islands). Geological Magazine, 131(6): 715-727. http://doi.org/10.1017/S0016756800012838

Martín-Moreno, R., 2010. La Pequeña Edad de Hielo en el Alto Teide (Tenerife, Islas Canarias). Ería, 83: 331-342.

Martínez de Pisón, E., Arozena, M., Beltrán, E. \& Romero, C., 2009. Los paisajes del Parque Nacional del Teide. Ed. Organismo Autónomos Parques Nacionales, pp., 203, Madrid.

Master, S., 2016. Gaet'ale- a reactivated thermal spring and potential tourist hazard in the Asale salt flats, Danakil Depression, Ethiopia. Journal of Applied Volcanology, 5: 1. http:// doi.org/10.1186/s13617-015-0042-x

Mateo, E., Martínez-Frías, J. \& Vegas, J., 2019. Lanzarote and Chinijo Islands Geopark: From Earth to Space. Springer, pp., 186, Cham.

Megerssa, L., Rapprich, V., Novotný, R., Verner, K., Erban, V., Legesse, L. \& Manaye, M., 2019. Inventory of key geosites in the Butajira Volcanic Field: perspective for the first geopark in Ethiopia. Geoheritage, 11: 1643-1653. http://doi org/10.1007/s12371-019-00393-y

Millán, M., 2011. La función didáctica del geoturismo. Propuesta para la Región de Murcia. Gran Tour: Revista de Investigaciones Turísticas, 4: 62-93.

Moufti, M., Németh1, K., El-Masry, N. \& Qaddah, A., 2013. Geoheritage values of one of the largest maar craters in the Arabian Peninsula: the Al Wahbah Crater and other volcanoes (Harrat Kishb, Saudi Arabia). Central European Journal Geosciences, 5(2): 254-271. http://doi.org/10.2478/ s13533-012-0125-8
National Geographic, 2010. What is geotourism? Center for Sustainable Destinations. Disponible en Internet: https:// www.nationalgeographic.com/maps/geotourism/

National Geographic Society, 2020. Geotourism Principles. Recuperado de www.nationalgeographic.com/maps/geotourism/geotourism-principles/

Newsome, D. \& Dowling, R., 2010. Geotourism: the tourism of geology and landscape. Goodfellow Publishers, pp., 320, Oxford.

Ólafsdóttir, R. \& Dowling, R., 2014. Geotourism and GeoparksA Tool for Geoconservation and Rural Development in Vulnerable Environments: A Case Study from Iceland. Geoheritage, 6(1): 71-87. http://doi.org/10.1007/s12371-013-0095-3

Ólafsdóttir, R. \& Tverijonaite, E., 2018. Geotourism: a systematic literature review. Geosciences, 8 (7), 234. http://doi. org $/ 10.3390 /$ geosciences 8070234

Olson, K. \& Dowling, R., 2018. Geotourism and Cultural Heritage. Geoconservation Research, 1(1): 37-41. http:// doi:10.30486/GCR.2018.540021

Panizza M., 2001. Geomorphosites: concepts, methods and example of geomorphological survey. Chinese Science Bulletin, 46: 4-6.

Pralong, J.P., 2006. Geotourism: A new form of tourism utilising natural landscapes and based on imagination and emotion. Tourism Review, 61(3): 20-25. https://doi.org/10.1108/ eb058476

Pereira, P., Pereira, D. \& Caetano Alves, M.I. 2007. Geomorphosite assessment in Montesinho Natural Park (Portugal). Geographica Helvetica, 62: 159-168. http://doi. org/10.5194/gh-62-159-2007

Pérez-Umaña, D., Quesada, A., De Jesús-Rojas, J., Zamorano, J., Dóniz-Páez, J. \& Becerra-Ramírez, R., 2019. Comparative Analysis of Geomorphosites in Volcanoes of Costa Rica, Mexico, and Spain. Geoheritage, 11(2): 545-559. http://doi.org/10.1007/s12371-018-0313-0

Pérez-Umaña, D., Quesada, A. \& Tefogoum G., 2020. Geomorphological heritage inventory of Irazú Volcano, Costa Rica. International Journal of Geoheritage and Parks, 8: 31-47. http://doi.org/10.1016/j.ijgeop.2019.12.001

Reynard, E. \& Panizza, M., 2005. Geomorphosites: definition, assessment and mapping: an introduction. Geomorphologie: Relief, Processus, Environnement, 11(3): 177-180.

Reynard, E., Fontana, G., Kozlik, L. \& Scapozza, C., 2007. A method for assessing the scientific and additional values of geomorphosites. Geographica Helvetica, 62(3): 148-158. http://doi.org/10.5194/gh-62-148-2007

Reynard, E., Perret, A., Bussard, J., Grangier, L. \& Martin, S., 2016. Integrated approach for the inventory and management of geomorphological heritage at the regional scale. Geoheritage, 8: 43-60. http://doi.org/10.1007/s12371-015-0153-0

Romero-Díaz, A. \& Belmonte, F., 2002: Los paisajes geomorfológicos de la región de Murcia como recurso turístico. Cuadernos de Turismo, 9: 103-122.

Różycka M. \& Migoń, P., 2018. Customer-oriented evaluation of Geoheritage -on the example of volcanic geosites in the West Sudetes, SW Poland. Geoheritage, 10(1): 23-37. http://doi.org/10.1007/s12371-017-0217-4

Ruban, D., 2015. Geotourism-A geographical review of the literatura. Tourism Management Perspectives, 15: 1-15. doi. org/10.1016/j.tmp.2015.03.005

Sánchez-Cortez, J. \& Simbaña-Tasiguano, M., 2018. Los Geoparques y su implantación en América Latina. Estudios Geográficos, LXXIX/285: 445-467. http://doi.org/10.3989/ estgeogr.201817

Serrano, E. \& González, J., 2005. Assessment of geomorphosites in natural protected areas: the Picos de Europa National Park (Spain). Géomorphologie: Relief, Processus, Environnement, 3: 197-208. 
Sigurdsson, H. \& Lopes, R., 2000. Volcanoes and Tourism. En: Sigurdsson (Ed.). Encyclopedia of volcanoes. Academic Press, San Diego, pp. 1283-1299.

Stokes, A.M., Cook, S.D. \& Drew, D., 2003. Geotourism: The New Trend in Travel. Travel Industry America and National Geographic Traveler, pp., 65, Washington DC.

Suhud, U. \& Allan, M., 2019. Exploring the impact of travel motivation and constraint on stage of readiness in the context of volcano tourism. Geoheritage, 11: 927-934. http:// doi.org/10.1007/s12371-018-00340-3

Tourtellot, J.B., 2000. Geotourism for Your Community. National Geographic Drafts, p. 2. Washington, DC: National Geographic.
Wang, L., Tian, M. Wen, X., Zhao, L., Song, J., Sun, M., Wang, H., Lan, Y. \& Sun, M., 2014. Geoconservation and geotourism in Arxan-Chaihe Volcano Area, Inner Mongolia, China. Quaternary International, 349: 384-391. http://doi. org/10.1016/j.quaint.2014.06.024

Wildpret de la Torre, W. \& Martín-Osorio, V., 2004: Flora vascular y vegetación. En: (AAVV): Parque Nacional del Teide. Ed. Esfagnos-MMA, Madrid, pp. 97-142.

Zangmo-Tefogoum, G., Quesada-Román, A. \& Pérez-Umaña, D., 2020. Geomorphosites inventory in the Eboga Volcano (Cameroon): contribution for geotourism promotion. Géomorphologie: Relief, Processus, Environnement, 26(1): 1933. http://doi.org/10.4000/geomorphologie.14006 